\title{
Identification of olfactory genes of a forensically important blow fly, Aldrichina grahami (Diptera: Calliphoridae)
}

\author{
Han Han ${ }^{\text {Equal first author, } 1}$, Zhuoying Liu ${ }^{\text {Equal first author, 1, } 2 \text {, Fanming Meng }}{ }^{\text {Corresp., } 1}$, Yangshuai Jiang ${ }^{1}$, Jifeng Cai ${ }^{\text {Corresp. } 1}$ \\ ${ }^{1}$ Department of Forensic Science, School of Basic Medical Sciences, Central South University, Changsha, Hunan, China \\ 2 Departments of Anesthesiology and Medicine, David Geffen School of Medicine at University of California Los Angeles, Los Angeles, the United States \\ Corresponding Authors: Fanming Meng, Jifeng Cai \\ Email address: mengfanming1984@163.com, cjfjifeng@163.com
}

Background $\square$ The time-length between the first colonization of necrophagous insect on the corpse and the beginning of investigation represents the most important forensic concept of minimum post-mortem inference (PMImin). Before colonization, the time spent by an insect to detect and locate a corpse could significantly influence the PMImin estimation. The olfactory system plays an important role in insect food foraging behavior. Proteins like odorant binding proteins, chemosensory proteins, odorant receptors (ORs), ionotropic receptors and sensory neuron membrane proteins represent the most important parts of this system. Exploration of the above genes and their necrophagous products should facilitate not only the understanding of their roles in forging but also their influence on the period before PMImin. Transcriptome sequencing has been wildly utilized to reveal the expression of particular genes under different temporal and spatial condition in a high throughput way. In this study, transcriptomic study was implemented on antennae of adult Aldrichina grahami (Aldrich) (Diptera: Calliphoridae), a necrophagous insect with forensic significance, to reveal the composition and expression feature of OBPs, CSPs, ORs, IRs and SNMPs genes at transcriptome level.

Method: Antennae transcriptome sequencing of $A$. grahami was performed using next-generation deep sequencing on the platform of BGISEQ-500. The raw data were deposited into NCBI ( PRJNA513084). All the transcripts were functionally annotated using GO and KEGG database. Differentially expressed genes (DEGs) were analyzed between female and male antennae. The transcripts of OBPs, CSPs, ORs, IRs and SNMPs were identified based on sequence feature. Phylogenetic development of olfactory genes of $A$. grahami with other species was analyzed using MEGA 5.0. RT-qPCR was utilized to verify gene expression generated from the transcriptome sequencing.

Results: In total, 14,193 genes were annotated in the antennae transcriptome based on the GO and the KEGG databases. We found that 740 DEGs were differently expressed between female and male antennae. Among those, 195 transcripts were annotated as candidate olfactory genes then checked by sequence feature. Of these, 27 OBPs, 1 CSPs, 49 ORs, 6 IRs and 2 SNMPs were finally identified in antennae of $A$. grahami. Phylogenetic development suggested that some olfactory genes may play a role in food forging, perception of pheromone and decomposing odors.

Conclusion: Overall, our results suggest the existence of gender and spatial expression differences in olfactory genes from antennae of $A$. grahami. Such difference is likely to greatly influence insect behavior around a corpse. In addition, candidate olfactory genes with predicted function provide valuable information for further studies of the molecular mechanisms of olfactory detection of forensically important fly species and thus, deepen our understanding of the period before PMImin. 


\section{Identification of olfactory genes of a forensically important \\ 2 blow fly, Aldrichina grahami (Diptera: Calliphoridae)}

4 Han Han $^{1 \#}$, Zhuoying Liu ${ }^{1,2 \#}$, Fanming Meng ${ }^{1 *}$, Yangshuai Jiang ${ }^{1}$, Jifeng Cai ${ }^{1 *}$

5 Department of Forensic Science, School of Basic Medical Sciences, Central South University,

6 Changsha, Hunan 410013, China;

7 2Departments of Anesthesiology and Medicine, David Geffen School of Medicine at University

8 of California Los Angeles, Los Angeles, the United States

$9 *$ Corresponding author:

10 Jifeng Cai, PhD and Fanming Meng

11 Changsha, Hunan 410013, China

12 Email address: cjf jifeng@163.com

13 \# These authors contributed equally to the article (Zhuoying Liu and Han Han) 


\section{ABSTRACT}

16 Background: The time-length between the first colonization of necrophagous insect on the

17 corpse and the beginning of investigation represents the most important forensic concept of

18 minimum post-mortem inference (PMImin). Before colonization, the time spent by an insect to

19 detect and locate a corpse could significantly influence the PMImin estimation. The olfactory

20 system plays an important role in insect food foraging behavior. Proteins like odorant binding

21 proteins (OBPs), chemosensory proteins (CSPs), odorant receptors (ORs), ionotropic receptors

22 (IRs) and sensory neuron membrane proteins (SNMPs) represent the most important parts of this

23 system. Exploration of the above genes and their necrophagous products should facilitate not

24 only the understanding of their roles in forging but also their influence on the period before

25 PMImin. Transcriptome sequencing has been wildly utilized to reveal the expression of

26 particular genes under different temporal and spatial condition in a high throughput way. In this

27 study, transcriptomic study was implemented on antennae of adult Aldrichina grahami (Aldrich)

28 (Diptera: Calliphoridae), a necrophagous insect with forensic significance, to reveal the

29 composition and expression feature of OBPs, CSPs, ORs, IRs and SNMPs genes at transcriptome

30 level.

31 Method: Antennae transcriptome sequencing of $A$. grahami was performed using next-

32 generation deep sequencing on the platform of BGISEQ-500. The raw data were deposited into

33 NCBI (PRJNA513084). All the transcripts were functionally annotated using GO and KEGG

34 database. Differentially expressed genes (DEGs) were analyzed between female and male 
antennae. The transcripts of OBPs, CSPs, ORs, IRs and SNMPs were identified based on sequence feature. Phylogenetic development of olfactory genes of $A$. grahami with other species was analyzed using MEGA 5.0. RT-qPCR was utilized to verify gene expression generated from the transcriptome sequencing.

39 Results: In total, 14,193 genes were annotated in the antennae transcriptome based on the GO

40 and the KEGG databases. We found that 740 DEGs were differently expressed between female

41 and male antennae. Among those, 195 transcripts were annotated as candidate olfactory genes

42 then checked by sequence feature. Of these, 27 OBPs, 1 CSPs, 49 ORs, 6 IRs and 2 SNMPs were

43 finally identified in antennae of A. grahami. Phylogenetic development suggested that some

44 olfactory genes may play a role in food forging, perception of pheromone and decomposing

45 odors.

46 Conclusion: Overall, our results suggest the existence of gender and spatial expression

47 differences in olfactory genes from antennae of $A$. grahami. Such difference is likely to greatly

48 influence insect behavior around a corpse. In addition, candidate olfactory genes with predicted

49 function provide valuable information for further studies of the molecular mechanisms of

50 olfactory detection of forensically important fly species and thus, deepen our understanding of

51 the period before PMImin.

52 Keywords antennae transcriptome, blow fly, minimum post-mortem interval, forensic

53 entomology, Aldrichina grahami. 


\section{INTRODUCTION}

56 Forensic entomology uses insects to help in determining origin, location, and time of death of a

57 human. The estimation of the postmortem interval by forensic entomologists is based on the

58 development of the insects that colonize the corpse. The time elapsed between the first insect

59 colonizing on the corpse to the start of forensic examination represents the most important

60 forensic concept of minimum post-mortem inference (PMImin). When and how the first insect

61 detects and colonizes the corpse could obviously affect the beginning of the PMImin. The length

62 of time between the time point of death and the first insect colonization on corpse was defined as

63 the pre-colonization interval (Pre-CI), which would account for large part of decomposition time

64 depending on various conditions (Tomberlin et al. 2011). Thus, the PMImin error could vary

65 from a few hours to a few days when pre-CI was overlooked unconsciously, which could limit

66 the application of forensic entomology. Some irritant compounds, such as volatile compounds

67 (VOCs), are produced during the process of corpse decomposition (Rosier et al. 2016). It is

68 believed that these VOCs provide clues for host detection and oviposition in necrophagous flies.

69 Studies have shown that these behaviors can be mediated by the olfactory system and may

70 exhibit gender difference (Wicker-Thomas 2007).

71 The insects' olfactory system is a highly specific and extremely sensitive chemical sensory

72 nervous system, formed during long-term evolution. Antennae are the main olfactory organs in

73 insects. They have critical roles in detecting environmental chemical signals and subsequently

74 affecting insect behaviors (Chang-Xiang Zhou 2015; Fadamiro 2011), such as mate choice, host 
75

76

77

searching, oviposition site selection, and toxic compound avoidance (Liu et al. 2018). Olfactory proteins are commonly expressed in olfactory tissue antennae and maxillary palp, or in nonolfactory like tentacles, lower lip whiskers, and so on (de Bruyne et al. 1999; Kwon et al. 2006). One study suggests that different types of olfactory-related proteins could participate in sensing different odors (Hallem \& Carlson 2006). Generally, olfactory-related proteins are classified as odorant binding proteins (OBPs), chemosensory proteins (CSPs), odorant receptors (ORs), ionotropic receptors (IRs), sensory neuron membrane proteins (SNMPs) and odor degrading enzymes (ODEs) (Gu et al. 2015; Leal 2013; Wang et al. 2017).

The OBPs and the CSPs represent the key step in the insect olfactory signaling process (Field 2010). They are small soluble proteins in the sensilla lymph, and when combined with chemical molecules form a conjugate which could be recognized by corresponding receptors (Gong et al. 2007; Pelosi et al. 2006). The OBPs are highly conserved protein, firstly discovered in Antheraea polyphemus (Vogt \& Riddiford 1981). Notably, many OBPs have binding preference or higher affinity to specific odor compounds (Maida et al. 2003; Pophof 2004). Based on the literature, OBPs can be divided into four sub-types according to sequence feature: 'Classical' OBPs, 'Dimer' OBPs, 'Minus-C' OBPs and 'Plus-C' OBPs (Campanini \& de Brito 2016; JingJiangcZhou 2004). In 2011, there is a study further classified the classical OBPs into three subfamilies, as pheromone-binding proteins (PBPs), general odorant-binding proteins (GOBPs) and antennal-binding protein X homologs (ABPXs) (Zhang et al. 2011). Compared OBPs, CSPs are mainly involved in insects' perception of chemical signals and exhibit multifarious functions 
95

96

97

98

99

100

101

102

103

104

105

106

107

108

109

110

111

112

113

114

(Emmanuelle Jacquin-Joly 2001; Mei et al. 2018).

The ORs are participants in chemosensory signal transduction processes. ORs have seven transmembrane domains and a specific reversed membrane topology (Benton 2006; Jacquin-Joly \& Merlin 2004; Peter J. Clyne 1999). In insects' olfactory nervous, there are two types of ORs: Conventional ORs and olfactory receptor co-receptor (ORCo), previously known as OR83b (Larsson et al. 2004; Smith 2007). The conventional ORs, a highly divergent family, respond to pheromones and volatile compounds (Carey et al. 2010; Mitchell et al. 2012; Vosshall et al. 2000). Compared with traditional ORs, ORCo is a highly-conserved family (Jones et al. 2005). They act as ion channel (Mitchell et al. 2012; Sato et al. 2008), but their involvement in olfactory transduction remains controversial (Zufall \& Domingos 2018).

The IRs are also membrane-bound chemosensory receptors located in the dendritic membrane of receptor neurons like ORs (Benton et al. 2009). Based on their function, IRs are divided into two types: the conserved "antennal IRs" and the species-specific "divergent IRs" (Benton et al. 2009; Rimal \& Lee 2018; Wang et al. 2016). The antennal IRs are mainly involved in the sensory process of odorant, while divergent IRs plays a role in taste (Benton et al. 2009; Croset et al. 2010; Wang et al. 2016).

Likewise, the SNMPs are transmembrane proteins, homologous to mammalian CD36 protein family (Nichols \& Vogt 2008; Rogers et al. 1997), and are important for odor detection (Hu et al. 2016). Subtypes SNMP1 and SNMP2 are organs specifically expressed at different locations (Rogers et al. 2001a; Rogers et al. 2001b; Rogers et al. 1997). Indeed, the SNMP1 is especially 
115

116

117

118

122

expressed in the dendritic membrane of olfactory receptor neurons, and functions as a pheromone induction (Rogers et al. 2001b; Vogt et al. 2009; Zhang et al. 2015a), whereas the SNMP2 is found in supporting cell (Forstner et al. 2008; Liu et al. 2013; Zhang et al. 2015a), but its function is uncertain.

Aldrichina grahami (Aldrich) (Diptera: Calliphoridae) is a common necrophagous insect of forensic importance. It feeds on corpses or feces and mainly distributes in the Palearctic and the partial Oriental regions. Research reported its intrusion into other parts of the world in the past decades (Sukontason et al. 2004; ZD 1992). A. grahami is a species with characteristic strong cold tolerance (Wang et al. 2018), and it could be the first and major insect species which locate and colonize on corpses in early spring and late autumn when temperature is relative low (Guo YD 2011; Kurahashi H 1984). This means seasonal distribution of $A$. grahami could be useful for the PMI estimation in cold environment. Moreover, the emission of VOCs from corpses could be reduce under the low temperature (Forbes et al. 2014). In addition, A. grahami should be able to detect VOCs of corpses even when it at relative low density. The report of myiasis by A. grahami shows that the olfactory system is also helpful in host detection (Liu 1980; Yinong Duan 2002). However, so far, there is no study about the olfactory system of A. grahami.

Considering that olfactory related proteins play a critical role in olfactory system, exploration of their genes and products should deepen our understanding of its behavior like food forging, locating, host recognizing and colonization as well as further improve methods for an accurate PMI estimation. 
135 In this study, the first antennal transcriptome analysis of $A$. grahami was performed using next

136 generation sequencing (NGS) to identify the genes of olfactory family from A. grahami.

137 Differences between female and male gene expression were analyzed. A set of putative OBPs, 138 CSPs, ORs, IRs and SNMP in A. grahami was annotated and the expression level was verified. 139 Additionally, different expression profiles of the olfactory related proteins between female and 140 male organs were explored. Finally, predicting function of olfactory genes was discussed based 141 on phylogenetic analysis.

\section{MATERIALS AND METHODS}

143

144

145

146

147

\section{Insect rearing}

The first generation of $A$. grahami was captured using pork as baits in Changsha, Hunan province, China. Adults were identified based on the description of Fan (ZD 1992). Both sexes were bred in plastic containers $(30 \mathrm{~cm} \times 30 \mathrm{~cm} \times 30 \mathrm{~cm})$ and reared with milk and sugar $(1: 1)$ as food sources to gain more individuals for sampling. The daylight regime was 12:12 (L: D) and the temperature in the rearing room was $25 \pm 2{ }^{\circ} \mathrm{C}$ with $70-80 \%$ relative humidity. Adult antennae were obtained from females and males under a dissecting microscope and flash-frozen in liquid nitrogen in $1.5 \mathrm{~mL}$ microcentrifuge tubes and then stored at $-80^{\circ} \mathrm{C}$ until used to isolate RNA.

\section{RNA isolation and quality assessment}

Total RNA samples of antennae were isolated using TRIzol Reagent according to the manufacturer's protocol (Invitrogen, USA). The quality of RNA was confirmed using a 
154 NanoVue UV-Vis spectrophotometer (GE Healthcare Bio-Science, Sweden), and RNA integrity

155 was verified using a standard 1\% agarose gel electrophoresis. Purification of RNA was carried

156 out using DNase I as per manufacturer's instructions (Takara, Japan).

\section{CDNA library preparation and sequencing}

158 Total RNA was treated by enriching poly-A tail mRNA with magnetic beads with OligodT, and

159 the desired RNA was obtained after purification. Subsequently, the RNA was fragmented with a

160 break buffer, and reverse transcribed with random N6 primers to synthesize cDNA double

161 strands to obtain double stranded DNA. The synthesized double-stranded DNA was flattened at

162 the end and phosphorylated at the 5' end, flattened at the $3^{\prime}$ end with sticky' $\mathrm{A}^{\prime}$, and connected

163 with adaptor. The ligation product was amplified by two specific primers then denatured by heat.

164 Single-stranded DNA was cyclized with a bridge primer to obtain a single-stranded circular

165 DNA library. Finally, the cDNA libraries were sequenced on the BGISEQ-500 sequencing

166 platform (BGI-Shenzhen, China).

\section{Sequence reads mapping, assembly and annotation}

168 Primarily, the raw reads were filtered by removing reads that contain adapters, poly nitrogen, and

169 low quality. The remaining high quality clean reads had a base quality 20\% lower than Q20.

170 Consequently, we calculated the Q20, Q30, GC-content and sequence duplication levels of the

171 clean data. All subsequent analyses were performed using high quality clean reads. Clean reads

172 were mapped to the $A$. grahami genome assembly (NCBI: PRJNA513084) by using HISAT2. 
173 (Parameter: --dta --phred64 unstranded --new-summary -x index -1 read_r1 -2 read_r2 (PE).)

174

175

176

177

178

179

180

181

182

183

184

185

186

187

188

189

190

191

\section{Analysis of differentially expressed genes}

The quantity of gene expression levels from male and female groups were performed using FPKM (Fragments per kilobase of transcript per million mapped reads). It was calculated with NCBI gtf file through gene length annotation. The count calculation was performed using the HTSeq (Anders et al. 2015). The DEGs between male and female groups were identified by the DEG-seq (an R package to identify differentially expressed genes from RNA-Seq data) (Wang et al. 2010). To improve the accuracy of the DEGs, the DEGs were filtered with a fold change $>2$ or $<0.5$, and the false discovery rates $(\mathrm{FDR})<0.05$ (Anders \& Huber 2010). Transcripts were annotated using Kyoto Encyclopedia of Genes and Genomes (KEGG) analysis (Kanehisa et al. 2008) and Gene Ontology (GO). The GO annotation of genes was obtained using BLast2GO software. DEGs were enriched via KEGG and GO database. A Fisher exact test was used to find the vital enrichment pathway in the study by taking the significance of $p$-value $<0.05$ and FDR $<$ 0.05 as thresholds.

\section{Identification of candidate transcripts}

The tBLASTn program was performed with available sequences of OBPs, CSPs, ORs IRs and SNMPs from other species as a 'query' to identify candidate genes that encoded putative OBPs, CSPs, ORs, IRs and SNMPs in A. granhmi, respectively. All candidate OBPs, CSPs ORs, IRs and SNMPs were manually checked by the BLASTp (http://blast.ncbi.nlm.nih.gov/Blast.cgi) 
192 search application. Soon after, the prediction opening reading frame (ORF) of the candidate

193 OBPs, CSPs, ORs, IRs and SNMPS genes was identified by the ORFfinder

194 (https://www.ncbi.nlm.nih.gov/orffiffiffinder/). Conserved domain was predicted utilizing Batch

195 CD-search (https://www.ncbi.nlm.nih.gov/Structure/bwrpsb/bwrpsb.cgi). The transmembrane

196 domains (TMDs) of IRs, ORs and SNMPs were predicted by TMHMM server (v2.0)

197 (http://www.cbs.dtu.dk/services/TMHMM/). The signal peptide of putative OBPs and CSPs were

198 predicted using Signa1P (v5.0) (http://www.cbs.dtu.dk/services/SignalP/) server version with the 199 default parameters.

\section{Quantitative real-time PCR analysis}

201 To compare the differential expression of chemosensory genes between female and male

202

203

204

205

206

207

208

209

210

211 antennal transcriptomes in $A$. grahami, the reads number of each olfactory-related gene was converted to FPKM (Livak \& Schmittgen 2001). Quantitative real-time PCR analysis (qRT-PCR) was performed to quantify the expression levels of olfactory-related genes in male and female antennae with rp49 as the reference gene (Rodrigues et al. 2017). Total RNA was extracted from 50 antennae obtained from females and males separately as described in the section of RNA isolation and quality assessment. The cDNA from antennae of both sexes was synthesized using the Goldenstar ${ }^{\mathrm{TM}}$ RT6 cDNA Synthesis Mix. One $\mu \mathrm{g}$ of total RNA from samples was used in reverse transcription in a total volume of $20 \mu \mathrm{L}$ reaction system to obtain the first-stand cDNA. The qRT-PCR was performed on an ABI 7500 using SYBR green dye (2×T5 Fast qPCR Mix) binding to double stranded DNA at the end of each elongation cycle. Primer sequences were 
212 designed by the Primer Premier 5.0 program (Table.S1). QRT-PCR was conducted using

213 previous method (Jia et al. 2016). In order to check reproducibility, qRT-PCR test for each

214 sample was performed with three technical replicates and three biological replicates.

215 The Relative quantification analyses among samples were performed using comparative

$2162^{\wedge-\Delta \Delta \mathrm{Ct}}$ method (Schmittgen \& Livak 2008).

\section{Tissue Expression Analysis}

218 The expression of OBPs, ORs and non-olfactory genes of different organs were evaluated by

219 qRT-PCR using the same procedure as the one for quantitative real-time PCR analysis. Female

220 antennae (FA), leg (FL), wing (FW), head (FH), and male antennae (MA), leg (ML), wing (MW),

221 head (MH) were collected from adult $A$. grahami. The Relative quantification analyses among

222 samples were also performed using comparative $2^{\wedge-\Delta \Delta \mathrm{Ct}}$ method.

\section{Phylogenetic analysis}

224 Protein sequences of Drosophila melanogaster, Calliphora stygia, Musca domestica and Lucilia cuprina were obtained from Uniprot (Apweiler et al. 2004). The phylogenetic development of OBPs, ORs IRs, SNMPs and CSP trees were constructed by MEGA 5.0 with neighbor-joining method utilizing default setting and 1,000 bootstraps respectively (Li et al. 2017).

\section{Overview of transcriptomes}


230 An average of $6.46 \mathrm{~GB}$ raw data were generated from each sample by reading the male and the

231 female's antenna samples. After removing adaptor sequences, low quality sequences, and N-

232 containing sequences, a mean of $48.35 \mathrm{Mb}$ clean reads were obtained for each sample (Table.S2).

233 The mean Q30 was about $89.0 \%$ for each sample. Clean reads from 6 samples, $74.83 \%$ to $78.58 \%$

234 were successfully mapped against the reference $A$. grahami genome (SRA: PRJNA513084). The

235 percentage of unique mapping reads was from $49.82 \%$ to $51.92 \%$ in each sample. Pearson

236 Correlation Coefficient between three biological replicates from the two groups (male and

237 female) had high repeatability (i.e., all $\mathrm{R}^{2} \geq 0.9731$ ).

\section{Gene prediction and annotation}

239 A total of 14,193 genes were annotated, including 11,327 known genes and 2,866 predicted novel genes. A total of 16,995 new transcripts were found, of which 9,460 belonged to newly

241 alternative splicing subtypes of known protein coding genes, 2,951 belonged to transcripts of

242 new protein coding genes, and the remaining 4,584 were long-noncoding RNA.

9667 genes were enriched by GO annotation. GO divided genes into three categories, representing the molecular functions, cellular component, and biological processes, respectively.

245 The first three categories that contain the largest number of genes are represented in Fig. 1. The

246 category includes binding (4708), cell (3617) and cellular process (3549).

247 In total, 7243 were functionally clustered into 6 KEGG categories including cellular processes, 248 environmental and genetic information processing, and diseases and metabolism. Among the 44 
249 sub-categories, "signal transduction" (1677) and "global and overview maps" (1397) were the 250 most enriched (Fig.S1).

251 Moreover, 195 candidate olfactory related transcripts were found based on the results of 252 annotation, including 36 OBPs (Table.1), 70 ORs (Table.2), 7 IRs (Table.S3), 1 CSP (Table.S4), 2532 SNMPs (Table.S5) and 9 non-olfactory genes (Fig.S2).

\section{Identification of olfactory genes of $\boldsymbol{A}$. grahami}

255 In total, 36 putative OBPs encoding sequences were found in the antennal transcriptome (Table.1)

256 with 5 having no signal peptide. 28 putative OBPs transcripts have intact open reading frames

257 (ORF) with the lengths ranging from 100 to 300 aa. After analysis, out of the 28 genes 26 were

258 selected with predicted domain belonging to pheromone/general odorant-binding protein (PhBP

259 or PBP_GOBP) family. According to the number and sites of conserved cysteines, $21 A$.

260 grahami OBPs transcripts shared structural characteristics of OBPs (i.e. having typical six

261 conserved cysteines) with other insects (Jia et al. 2016), including 4 'Minus-C'OBPs with C

262 missing, and one 'Plus-C' OBPs with more than six conserved cysteines and a proline (Fig.2).

263 Seventy candidate ORs transcripts were found in the results of annotation (Table.2). Of these,

26449 genes which contained 3-8 transmembrane domains (TMDs) and conservative domain (7tm_6

265 superfamily) were selected for further analysis. Seven putative IRs were identified in both male

266 and female $A$. grahami antennal transcriptomes (Table.S3) including six IRs had 3-8TMDs. One

267 transcript encoding putative CSP (A. grahami OF01513) (Table.S4) had a signal peptide and 
268

269

270

271

272

273

274

275

276

277

278

279

280

281

282

283

only two conserved cysteine residues. Two transcripts (A. grahami OF05479 and OF07379)

which contained two TMDs with 450-600 aa were identified as SNMPs (Table.S5).

\section{Gene expression differences between female and male}

Based on the RNA-Seq by Expectation Maximization selection, 740 differentially expressed genes (DEGs) were chosen between female and male antennae. In total, 357 up-regulated and 383 down-regulated genes were found in male antennae. Among the DEG results, 21

differentially expressed olfactory genes, including 4 OBPs, 8 ORs and 9 other genes (which were enriched in the term of olfactory transduction function in KEGG) were found between the females and the males. The $\log _{2}$ (Aldrich_M/Aldrich_F) ranged from 1.00 to 11.01 in the up-regulated genes. Meanwhile, in the down-regulated genes, the $\log _{2}$ (Aldrich_M/Aldrich_F) ranged from -1.00 to 10.64 .

\section{Sex-specific expression}

Based on the transcriptome results, 76 genes exhibited sex-specific expression, among which 37 genes only found in male antennae and 39 genes only present in female antennae. In addition, among the 195 candidate olfactory genes, 10 genes were male-specific and 7 were femalespecific genes. These include 5 OBPs and 3 ORs male-specific and 2 ORs female-specific.

For qRT-PCR verification, we selected two male-specific and one female-specific gene with relatively high expression based on the FPKM. These genes were $A$. grahami OF03173, OF08934 and BGI_novel_G000488 in males, OF12341 in females, respectively. Ten DEGs were 
287 selected for qRT-PCR verification (Fig.3, Fig.4 and Fig.5).

288 The qRT-PCR results supported the data obtained by transcriptome sequencing. The

289 expression levels of 3 OBPs genes (A. grahami OF08228, OF03173 and OF08934) in male

290 antennae were significantly upregulated in qRT-PCR results and consistent with those obtained

291 by RNA-seq (Fig.3), suggesting that these genes were gender specific. In addition, the

292 expression of 6 ORs genes in qRT-PCR analyses was consistent with the results of our

293 transcriptome (Fig.4). The A. grahami OF05347 and BGI_novel_G000488 were highly

294 expressed in male, while the rest of 4 genes were significantly expressed in female. Among these

295 genes, OF05347 and OF11636 both exhibited gender specific expression. Particularly, OF05347

296 was highly expressed in male antennae, while $A$. grahami OF11636 was in female antennae

297 (Fig.4). The qRT-PCR results of 4 non-olfactory genes showed that only A. grahami OF12624

298 was different between female and male (Fig.5).

299 Expression of putative olfactory genes in different organs

300 Thirteen genes including 3 OBPs, 6 ORs and 4 non-olfactory genes were selected to explore the

301 level of expression in olfactory and non-olfactory organs (head, leg and wing) in both females

302 and males A. grahami. Three OBPs were highly expressed in head than other organs (Fig.3). The

303 OF08934 was highly expressed in both female head and in male antennae both. This may be due

304 to the relative high expression of OF08934 in the female's mouth parts. 
305 In addition, the 6 ORs (OF05347, OF11636, OF03270, OF03271, OF12341 and BGI-novel-

306 G000488) genes were significantly upregulated in antennae, compared with other organs (Fig.4).

307 Among these genes, both OF05347 and OF11636 both exhibited organ- and gender-specific

308 expression.

The 3 of 4 non-olfactory genes showed no difference in female and male antennae (Fig.5).

However, difference was found between organs as well as genders. A. grahami OF12624 was

mainly expressed in the head and antennae of male, BGI-novel-G000012 was expressed in the

312 head and wing of female, and BGI-novel-G000010 were expressed in the leg of females and

313 males. However, for A. grahami OF04198 expression, there was no difference between male and 314 female.

\section{Phylogenetic analysis of olfactory genes}

316 A phylogenic tree of OBPs was constructed using OBPs of $A$. grahami with $D$. melanogaster

317 (40), C. stygia (20), M. domestica (11), and L. cuprina (10) (Fig.6). Some pairs of A. grahami

318 OBPs were paralogous genes, such as $A$. grahami OF12161/OF12164 and A. grahami

319 OF12163/OF12164. In addition, the OBPs of A. grahami, C. stygia, and L. cuprina were grouped

320 with higher homology, e.g. A. grahami OF00694/C. stygia OBP11, A. grahami OF08066/C.

321 stygia OBP5, A. grahami OF08068/C. stygia OBP15, A. grahami OF08069/L. cuprina OBP2

322 and so on. Moreover, A. grahami OF12159, OF12160, OF12166, OF12165, OF12161, OF12162,

323 OF12163 and OF12164 was clustered with D. melanogaster LUSH (an OBP with a combination

324 of pheromone). A. grahami OF03991 was clustered with D. melanogaster 83a/83b (a class of 
325

326

327

328

329

330

331

332

333

334

335

336

OBPs that were co-expressed with LUSH and related to pheromone detection), and OF06321 with D. melanogaster 28a.

The phylogenetic tree of $A$. grahami ORs with D. melanogaster, C. stygia, M. domestica and $L$. cuprina showed that ORs were clustered into multiple groups. But the A. grahami OF07668 was clustered into the type of ORCo. All ORCos were grouped with high support value (99\%) (Fig.7).

For IRs analysis, A. grahami OF11318 was clustered into a group of IR8a/25a (Fig.S3). The IR8a/25a has been proved to be IR co-receptors in other species (Abuin et al. 2011; Benton et al. 2009). A. grahami OF09221 was clustered into "antennal IRs" with high supporting value. Specifically, A. grahami OF00615 belongs to "divergent IRs", a family of proteins involved in taste detection and evaluation of ingested food before entering the digestive system (Croset et al. 2010). Moreover, IR25a and IR8a fell into a conserved branch in the phylogenetic tree, which was consistent with the results obtained in Anoplophora glabripennis (Hu et al. 2016).

The CSPs of three different species had relatively high conservativeness. According to the motif analysis, CSPs were found to be an extremely conservative proteins family (Zhao et al. 2018) (Fig.S4). The 2 SNMPs found in the present study exhibited high conversation with the $A$. grahami OF05479 clustering into SNMP2 (Fig.S5).

\section{DISCUSSION}

The PMImin estimation is a major task of forensic investigation and research. But the period (pre-CI) between the point of death happened and the beginning of PMImin represent a non- 
344 negligible factor which may greatly influence the PMImin estimation. Exploration on the

345 mechanism beneath the corpse locating behavior of necrophagous insect should facilitate the

346 understanding of pre-CI, which will definitely improve the estimation of PMI. It has been well

347 demonstrated that insects' olfactory system plays a major role in their food foraging behavior.

348 Related genes and their products like OBPs, ORs, CSPs, IRs and SNMPs, were responsible for

349 the odor detection and signal transduction. A. grahami is usually one of the first arrived insect

350 group on corpses. Moreover, its obvious cold tolerance and seasonal distribution pattern could be

351 applied as a potential "season stamp" of the time of death in the PMI estimation, especially in the

352 period when other insects are inactive (Kurahashi H 1984; Kurahashi H 1991). Therefore, the

exploration of olfactory genes and their expression feature of $A$. grahami could provide

candidate genes for further research on mechanism of corpse location and factors determining the time length before insect colonization. other invertebrates (Glaser et al. 2013; Olafson et al. 2010) (Fig.1), especially the function of binding is the most enrich term. In general the number of olfactory gene family candidate transcripts were consistent with that of other species (Liu et al. 2012; Pitts et al. 2011; Riveron et al. 2013), except for CSP and IR. We also found that the expression difference of olfactory genes

361 between the sexes is consistent to that of other insects (Leitch et al. 2015; Li et al. 2018; Yuan et

362 al. 2019; Zhao et al. 2018). In addition, some olfactory genes are highly expressed in other 
363 organs (head, leg or wing) rather than antennae. In fact, this is common in other research results 364 (Li et al. 2018; Zhao et al. 2018).

The premier step in pheromone or odorant perception is their interaction with members of the OBP and the CSP families (Vieira \& Rozas 2011). The OBPs and CSPs mainly transport odor molecules and bind to receptors on dendrites through lymphatics, and served as a link between the external environment stimuli and odor receptor. In A. grahami antennae, three OBPs namely, OF08228, OF03173 and OF08934 were sex-specifically expressed in male. Interestingly, these three genes were also highly expressed in other organs compared to antennae, indicating that those genes were not solely involved in olfactory transduction. In fact, study had reported that

372 part of OBPs could function in the gustatory system of the insect (Jeong et al. 2013).

373 Additionally, two PBPs were also male-enriched. Those PBPs may play an essential function in 374 male's perception to sex pheromone components emitted from female according to previous researches (Allen \& Wanner 2011; Gu et al. 2013). A study of D. melanogaster has reported that a single OBP could bind with different odors (Liu et al. 2017). For example, D. melanogaster OBP LUSH was sensitive to alcohols and 11-cis vaccenyl acetate which were found in both the active and the advanced decay stages of corpse (Paczkowski et al. 2015). The eight OBPs of $A$. grahami clustering with LUSH on the topological tree (Fig.6) suggested their similar function and sensitiveness to alcohols and esters. Specifically, A. grahami OF00694 and D. melanogaster

$38184 \mathrm{a}$ were clustered into the same branch in topological tree. The latter were located in the 382 coeloconic sensilla and functioned in detection of organic acids and amines (Larter et al. 2016). 
383 Since organic acids and amines are vital voltaic compound during corpse decomposition, and

384 mainly appear in the active and the advanced decay stages. These OBPs genes may play a key

385 role in the odor preference of A. grahami to corpse. Although further studies are needed for

386 identification of the specific types of odor molecules and how they may affect the blowfly.

387 ORs and OBPs are essential in the response of insect receptors to odors (Barbosa et al. 2018).

388 In our study, 48 transcripts were typical ORs and one (A. grahami OF07668) was the atypical co-

389 receptor ORCo. ORCo was previous reported highly conserved between species (Butterwick et al.

390 2018; Jones et al. 2005), indicating that A. grahami OF07668 should be subdivided as ORCo.

391 Notably, ORCo is an important component in the regulation of insect smell, which indicates the

392 position of other traditional ORs in olfactory sensory neurons (OSNs) of membranes (Liu et al.

393 2015). In the present study, we found gender differences in the expression level of some ORs.

394 On the one hand, this could be explained by male and female difference in sensitiveness to

395 similar odor stimuli. On the other hand, these differently expressed ORs may be involved in both

396 sex pheromone and food resource detection. Based on previous a study on ORs (Leitch et al.

397 2018), different types of ORs have diverse responses to odors. Functional analysis of $D$.

398 melanogaster odorant responses demonstrated their role in the detection of alcohol, phenols, and

399 esters, all of which are emitted during biological decomposition (Munch \& Galizia 2016). Based

400 on previous research led by (Forbes et al. 2014), alcohols were the main compounds volatilized

401 from corpses in winter. Some other studies suggested that mono-alcohol was attractive to flies

402 (Frederickx et al. 2012; Paczkowski et al. 2012). The ORs of A. grahami identified in our study 
403 were clustered with that of $D$. melanogaster in the phylogenetic tree. For instance, A. grahami

404 OF00900 and D. melanogaster OR43a had high supporting value and clustered together. D.

405 melanogaster OR43a had a sharp response to the 1-hexanol (Munch \& Galizia 2016).

406 Furthermore, it has been reported that 1-hexanol was the component of volatile compounds

407 during decomposition (Paczkowski et al. 2015). The former could be an important receptor of $A$.

408 grahami in the detection of volatile compounds of corpses and affect foraging behavior, such as

409 locating the corpses.

410 IRs are also transmembrane proteins which comprise the ion channels in olfactory reaction

411 (Gu et al. 2019). IRs of D. melanogaster have been proved useful in the detection of amines and

412 acids (Benton et al. 2009; Yao et al. 2005). In present study, there was no significant difference

413 in the expression of 6 IRs between females and males. Although, one candidate IR was

414 homologous to the antennal IRs of D. melanogaster (Fig.S3) was sensitive to individual

415 decomposition compounds (e.g., propionic acid, ammonia, butyric acid and putrescine) between

416 male and female (Rytz et al. 2013). Antennal IRs represent the basis for an accurate odor

417 response from antenna neuron subgroup (Croset et al. 2010). We found that A. grahami

418 OF09221 was homologous to D. melanogaster IR64a. Since the later gene was sensitive to acid-

419 sensing (Ai et al. 2010) and organic acids, both of which are components of VOCs. A. grahami

420 OF09221 is likely to play an acid-sensing role in the process of detecting corpses. Additionally,

421 A. grahami OF11318 was rooted in the IR8a/25a in phylogenetic tree suggesting that it should be

422 an ancestor the conserved member of IRs family. Besides the antennal IRs and the co-expressed 
423 receptor IRs mentioned above, the divergent IRs represent a large part of total IRs revealed by

424 the present study. These divergent IRs are a type of proteins expressed in gustatory organs as

425 taste receptors (Croset et al. 2010).

426 CSPs are a group of soluble carrier proteins harboring a similar function to that of OBPs

427 (Wanner et al. 2004). We identified a single putative CSP transcript and CSP protein in $A$.

428 grahami. Therefore, this protein is less present in A. grahami versus other species (Wanner et al.

429 2004; Zhang et al. 2015b; Zhou et al. 2010). The reason for this difference is still unclear. The

430 expression level, organ or species specificity were all possible.

431 In general, SNMPs are conversed in insects with limit family members (Qiu et al. 2018).

432 Similar to previous studies, we identified 2 SNMPs (Liu et al. 2014; Liu et al. 2013). Based on

433 the phylogenetic analysis, the differently expressed $A$. grahami OF05479 is clustered into

434 SNMP2, which is a protein that considered to be an important component of protecting olfactory

435 function (Blankenburg et al. 2019) (Fig.S5). In addition, we have found that $A$. grahami

436 OF07379 and L. cuprina SNMP3 were gathered in the same cluster, indicating that they possibly

437 have a similar function. And, there are no reporters about SNMP3 in present. However, $L$.

438 cuprina SNMP3 has high homology with SNMP1, which is a protein necessary for pheromone

439 detection in other species (Leitch et al. 2015; Rogers et al. 1997).

440 In addition to the conventional protein family mentioned above, 9 non-olfactory genes

441 possibly related to olfactory transduction have also been revealed by our transcriptome. Four of

442 the 9 genes (A. grahami BGI_novel_G000010,BGI_novel_G000012, OF04198 and OF12624) 
443 were differently expressed when male and female antennae were compared. Based on the

444 annotation results, these non-olfactory genes could be participant in both sensory system and

445 signal transduction in A.grahami olfactory system (Table S6).

\section{CONCLUSION}

447 Our current investigation is the first comprehensive analysis of antennal transcriptome from the

448 forensically important insect, A. grahami. Particularly, we determined gender and organ-

449 specifically expressed olfactory genes of $A$. grahami and discussed their potential functions in

450 necrophagous behavior. Further studies should focus on the co-relationship between specific

451 genes and VOCs components emitted by the corpse, as well as one the functional differences of

452 particular olfactory gene from various necrophagous insects.

453 In conclusion, olfactory genes found in present paper should provide important information

454 that can be used in the future for functional studies of $A$. grahami olfactory-associated genes and

455 other forensic related flies. Moreover, our findings will facilitate the exploration of olfactory

456 mechanisms in necrophagous blowfly species as well as improve PMImin estimation during

457 forensic investigations.

\section{Funding}

459 This work was supported by the National Natural Science Foundation of China (grant number

$46081571855 ; 81901923$ ) and Science Foundation of Hunan Province (2017SK2015).

\section{Conflict of interest}


462 We declare that we have no financial and personal relationships with other people or

463 organizations that can inappropriately influence our work; there is no professional or other

464 personal interest of any nature or kind in any product, service and/or company that could be

465 construed as influencing the position presented in, or the review of, the manuscript entitled.

\section{Availability of data and materials}

467 The RNA high-throughput sequencing data has been submitted to NCBI, Sequence data: NCBI:

468 PRJNA577237. Aldrichina grahami genome sequence data: NCBI: PRJNA513084.

469 Supplementary Materials: Table S1: The primer of the genes of A.grahami. Table S2:

470 Clean reads quality metrics from the A. grahami, Table S3: Unigenes of candidate ionotropic

471 receptors in A. grahami. Table S4: Unigenes of candidate chemosensory proteins in A. grahami.

472 Table S5: Unigenes of candidate sensory neuron membrane proteins in A. grahami. Table S6:

473 Enrichment Results of Differential Gene KEGG Pathway. Fig S1: KEGG (Kyoto Encyclopedia

474 of Genes and Genomes) pathway analysis. Fig S2: KEGG (Kyoto Encyclopedia of Genes and

475 Genomes) enrichment of differential genes. Fig S3: Phylogenetic tree of putative IRs from $A$.

476 grahami and other insects. Fig S4: Phylogenetic tree and motif analysis of putative CSPs from $A$.

477 grahami and other insects. Fig S5: Phylogenetic tree of putative SNMPs from A. grahami and

478 other species. 
481

482

483

484

485

486

487

488

489

490

491

492

493

494

495

496

497

498

499

500

501

502

503

504

505

506

507

508

509

510

511

512

513

514

515

516

517

518

519

Abuin L, Bargeton B, Ulbrich MH, Isacoff EY, Kellenberger S, and Benton R. 2011. Functional architecture of olfactory ionotropic glutamate receptors. Neuron 69:44-60. 10.1016/j.neuron.2010.11.042

Ai M, Min S, Grosjean Y, Leblanc C, Bell R, Benton R, and Suh GS. 2010. Acid sensing by the Drosophila olfactory system. Nature 468:691-695. 10.1038/nature09537

Allen JE, and Wanner KW. 2011. Asian corn borer pheromone binding protein 3, a candidate for evolving specificity to the 12-tetradecenyl acetate sex pheromone. Insect Biochem Mol Biol 41:141-149. 10.1016/j.ibmb.2010.10.005

Anders S, and Huber W. 2010. Differential expression analysis for sequence count data. Genome Biol 11:R106. 10.1186/gb-2010-11-10-r106

Anders S, Pyl PT, and Huber W. 2015. HTSeq--a Python framework to work with high-throughput sequencing data. Bioinformatics 31:166-169. 10.1093/bioinformatics/btu638

Apweiler R, Bairoch A, Wu CH, Barker WC, Boeckmann B, Ferro S, Gasteiger E, Huang H, Lopez R, Magrane M, Martin MJ, Natale DA, O'Donovan C, Redaschi N, and Yeh LS. 2004. UniProt: the Universal Protein knowledgebase. Nucleic Acids Res 32:D115-119. 10.1093/nar/gkh131

Barbosa AJM, Oliveira AR, and Roque ACA. 2018. Protein- and Peptide-Based Biosensors in Artificial Olfaction. Trends Biotechnol 36:1244-1258. 10.1016/j.tibtech.2018.07.004

Benton R. 2006. On the ORigin of smell: odorant receptors in insects. Cell Mol Life Sci 63:1579-1585. 10.1007/s00018-006-6130-7

Benton R, Vannice KS, Gomez-Diaz C, and Vosshall LB. 2009. Variant ionotropic glutamate receptors as chemosensory receptors in Drosophila. Cell 136:149-162. 10.1016/j.cell.2008.12.001

Blankenburg S, Cassau S, and Krieger J. 2019. The expression patterns of SNMP1 and SNMP2 underline distinct functions of two CD36-related proteins in the olfactory system of the tobacco budworm Heliothis virescens. Cell Tissue Res 378:485-497. 10.1007/s00441-019-03066-y

Butterwick JA, Del Marmol J, Kim KH, Kahlson MA, Rogow JA, Walz T, and Ruta V. 2018. Cryo-EM structure of the insect olfactory receptor Orco. Nature 560:447-452. 10.1038/s41586-018-0420-8

Campanini EB, and de Brito RA. 2016. Molecular evolution of Odorant-binding proteins gene family in two closely related Anastrepha fruit flies. BMC Evol Biol 16:198. 10.1186/s12862-016-0775-0

Carey AF, Wang G, Su CY, Zwiebel L, and Carlson JR. 2010. Odorant reception in the malaria mosquito Anopheles gambiae. Nature 464:66-71. 10.1038/nature08834

Chang-Xiang Zhou XS, Feng Mi, Jingyuan Chen, Man-Qun Wang. 2015. Antennal Sensilla in the Parasitoid Sclerodermus sp. (Hymenoptera: Bethylidae). Journal of Insect Science, 15.

Croset V, Rytz R, Cummins SF, Budd A, Brawand D, Kaessmann H, Gibson TJ, and Benton R. 2010. Ancient protostome origin of chemosensory ionotropic glutamate receptors and the evolution of insect taste and olfaction. PLoS Genet 6:e1001064. 10.1371/journal.pgen.1001064

de Bruyne M, Clyne PJ, and Carlson JR. 1999. Odor coding in a model olfactory organ: the Drosophila maxillary palp. J Neurosci 19:4520-4532.

Emmanuelle Jacquin-Joly RGV, Marie-Christine François, Patricia Nagnan-Le Meillour. 2001. Functional and Expression Pattern Analysis of Chemosensory Proteins Expressed in Antennae and Pheromonal Gland of Mamestra brassicae. Chem Senses 26:833-844.

Peer) reviewing PDF | (2019:12:44386:2:1:NEW 24 Jun 2020) 
520

521

522

523

524

525

526

527

528

529

530

531

532

533

534

535

536

537

538

539

540

541

542

543

544

545

546

547

548

549

550

551

552

553

554

555

556

557

558

559

560

Fadamiro PDLCKRSHY. 2011. Abundance of antennal chemosensilla in two parasitoid wasps with different degree of host specificity may explain sexual and species differences in their response to host-related volatiles. Microscopy Research\&Technique 74:900-909.

Field JJZFGVXLHCSRLJRLM. 2010. Genome annotation and comparative analyses of the odorant - binding proteins and chemosensory proteins in the pea aphid Acyrthosiphon pisum. Insect Mol Biol 19:113-122.

Forbes SL, Perrault KA, Stefanuto PH, Nizio KD, and Focant JF. 2014. Comparison of the decomposition VOC profile during winter and summer in a moist, mid-latitude (Cfb) climate. PLoS One 9:e113681. 10.1371/journal.pone.0113681

Forstner M, Gohl T, Gondesen I, Raming K, Breer H, and Krieger J. 2008. Differential expression of SNMP-1 and SNMP-2 proteins in pheromone-sensitive hairs of moths. Chem Senses 33:291-299. 10.1093/chemse/bjm087

Frederickx C, Dekeirsschieter J, Verheggen FJ, and Haubruge E. 2012. Responses of Lucilia sericata Meigen (Diptera: Calliphoridae) to cadaveric volatile organic compounds. J Forensic Sci 57:386-390. 10.1111/j.15564029.2011.02010.x

Glaser N, Gallot A, Legeai F, Montagne N, Poivet E, Harry M, Calatayud PA, and Jacquin-Joly E. 2013. Candidate chemosensory genes in the Stemborer Sesamia nonagrioides. Int J Biol Sci 9:481-495. 10.7150/ijbs.6109

Gong DP, Zhang HJ, Zhao P, Lin Y, Xia QY, and Xiang ZH. 2007. Identification and expression pattern of the chemosensory protein gene family in the silkworm, Bombyx mori. Insect Biochem Mol Biol 37:266-277. 10.1016/j.ibmb.2006.11.012

Gu SH, Zhou JJ, Wang GR, Zhang YJ, and Guo YY. 2013. Sex pheromone recognition and immunolocalization of three pheromone binding proteins in the black cutworm moth Agrotis ipsilon. Insect Biochem Mol Biol 43:237-251. 10.1016/j.ibmb.2012.12.009

Gu T, Huang K, Tian S, Sun Y, Li H, Chen C, and Hao D. 2019. Antennal transcriptome analysis and expression profiles of odorant binding proteins in Clostera restitura. Comp Biochem Physiol Part D Genomics Proteomics 29:211-220. 10.1016/j.cbd.2018.12.002

Gu XC, Zhang YN, Kang K, Dong SL, and Zhang LW. 2015. Antennal Transcriptome Analysis of Odorant Reception Genes in the Red Turpentine Beetle (RTB), Dendroctonus valens. PLoS One 10:e0125159. 10.1371/journal.pone.0125159

Guo YD CJ, Tang ZC, Feng XO, Lin Z, Yong F. 2011. Application of Aldrichina grahami (Diptera, Calliphoridae) for forensic investigation in central-south China. Romanian Journal Of Legal Medicine 19:55-58. 10.4323/rjlm.2011.55

Hallem EA, and Carlson JR. 2006. Coding of odors by a receptor repertoire. Cell 125:143-160. 10.1016/j.cell.2006.01.050

Hu P, Wang J, Cui M, Tao J, and Luo Y. 2016. Antennal transcriptome analysis of the Asian longhorned beetle Anoplophora glabripennis. Sci Rep 6:26652. 10.1038/srep26652

Jacquin-Joly E, and Merlin C. 2004. Insect olfactory receptors: contributions of molecular biology to chemical ecology. J Chem Ecol 30:2359-2397.

Jeong YT, Shim J, Oh SR, Yoon HI, Kim CH, Moon SJ, and Montell C. 2013. An odorant-binding protein required for suppression of sweet taste by bitter chemicals. Neuron 79:725-737. 10.1016/j.neuron.2013.06.025

Jia XJ, Wang HX, Yan ZG, Zhang MZ, Wei CH, Qin XC, Ji WR, Falabella P, and Du YL. 2016. Antennal transcriptome and differential expression of olfactory genes in the yellow peach moth, Conogethes punctiferalis

Peer) reviewing PDF | (2019:12:44386:2:1:NEW 24 Jun 2020) 
561

562

563

564

565

566

567

568

569

570

571

572

573

574

575

576

577

578

579

580

581

582

583

584

585

586

587

588

589

590

591

592

593

594

595

596

597

598

599

600

601

(Lepidoptera: Crambidae). Sci Rep 6:29067. 10.1038/srep29067

Jing-JiangcZhou WH, Guo-An Zhang, John A Pickett, Linda M Field. 2004. "Plus-C" odorant-binding protein genes in two Drosophila species and the malaria mosquito Anopheles gambiae. . Gene 327:117-129.

Jones WD, Nguyen TA, Kloss B, Lee KJ, and Vosshall LB. 2005. Functional conservation of an insect odorant receptor gene across 250 million years of evolution. Curr Biol 15:R119-121. 10.1016/j.cub.2005.02.007

Kanehisa M, Araki M, Goto S, Hattori M, Hirakawa M, Itoh M, Katayama T, Kawashima S, Okuda S, Tokimatsu T, and Yamanishi Y. 2008. KEGG for linking genomes to life and the environment. Nucleic Acids Res 36:D480-484. 10.1093/nar/gkm882

Kurahashi H KS, Shudo C. 1984. Seasonal prevalence of adult fly and life cycle of Aldrichina grahami (Aldrich) in Tokyo. Med Entomol Zool 35:261-267.

Kurahashi H KS, Shudo C. 1991. Seasonal migration of Japanese blow flies, Aldrichina grahami (Aldrich) and Calliphora nigribarbis Vollenhoven, observed by a mark and recapture method on Hachijo Island, Tokyo. Med Entomol Zool 42:57--59.

Kwon HW, Lu T, Rutzler M, and Zwiebel L. 2006. Olfactory responses in a gustatory organ of the malaria vector mosquito Anopheles gambiae. Proc Natl Acad Sci U S A 103:13526-13531. 10.1073/pnas.0601107103

Larsson MC, Domingos Al, Jones WD, Chiappe ME, Amrein H, and Vosshall LB. 2004. Or83b encodes a broadly expressed odorant receptor essential for Drosophila olfaction. Neuron 43:703-714. 10.1016/j.neuron.2004.08.019

Larter NK, Sun JS, and Carlson JR. 2016. Organization and function of Drosophila odorant binding proteins. Elife 5. 10.7554/eLife. 20242

Leal WS. 2013. Odorant reception in insects: roles of receptors, binding proteins, and degrading enzymes. Annu Rev Entomol 58:373-391. 10.1146/annurev-ento-120811-153635

Leitch O, Lennard C, Paul Kirkbride K, and Anderson A. 2018. Drosophila melanogaster odorant receptors as volatile compound detectors in forensic science: a proof-of-concept study. Anal Bioanal Chem 410:77397747. 10.1007/s00216-018-1390-2

Leitch O, Papanicolaou A, Lennard C, Kirkbride KP, and Anderson A. 2015. Chemosensory genes identified in the antennal transcriptome of the blowfly Calliphora stygia. BMC Genomics 16:255. 10.1186/s12864-0151466-8

Li H, Wang P, Zhang L, Xu X, Cao Z, and Zhang L. 2018. Expressions of Olfactory Proteins in Locust Olfactory Organs and a Palp Odorant Receptor Involved in Plant Aldehydes Detection. Front Physiol 9:663. 10.3389/fphys.2018.00663

Li K, Wei H, Shu C, Zhang S, Cao Y, Luo C, and Yin J. 2017. Identification and comparison of candidate odorant receptor genes in the olfactory and non-olfactory organs of Holotrichia oblita Faldermann by transcriptome analysis. Comp Biochem Physiol Part D Genomics Proteomics 24:1-11. 10.1016/j.cbd.2017.07.001

Liu C, Zhang J, Liu Y, Wang G, and Dong S. 2014. Expression of SNMP1 and SNMP2 genes in antennal sensilla of Spodoptera exigua (Hubner). Arch Insect Biochem Physiol 85:114-126. 10.1002/arch.21150

Liu JB, Wu H, Yi JQ, Song ZW, Li DS, and Zhang GR. 2018. Transcriptome characterization and gene expression analysis related to chemoreception in Trichogramma chilonis, an egg parasitoid. Gene 678:288-301. 10.1016/j.gene.2018.07.065

Liu NY, Zhu JY, Zhang T, and Dong SL. 2017. Characterization of two odorant binding proteins in Spodoptera exigua 
602

603

604

605

606

607

608

609

610

611

612

613

614

615

616

617

618

619

620

621

622

623

624

625

626

627

628

629

630

631

632

633

634

635

636

637

638

639

640

641

642

reveals functional conservation and difference. Comp Biochem Physiol A Mol Integr Physiol 213:20-27. 10.1016/j.cbpa.2017.08.002

Liu S, Rao XJ, Li MY, Feng MF, He MZ, and Li SG. 2015. Identification of candidate chemosensory genes in the antennal transcriptome of Tenebrio molitor (Coleoptera: Tenebrionidae). Comp Biochem Physiol Part D Genomics Proteomics 13:44-51. 10.1016/j.cbd.2015.01.004

Liu S, Zhang YR, Zhou WW, Liang QM, Yuan X, Cheng J, Zhu ZR, and Gong ZJ. 2013. Identification and characterization of two sensory neuron membrane proteins from Cnaphalocrocis medinalis (Lepidoptera: Pyralidae). Arch Insect Biochem Physiol 82:29-42. 10.1002/arch.21069

Liu Y. 1980. A Case of Gastrointestinal Myiasis Caused by Aldrichina genus. Acta Medicinae Universitatis Scientiae et Technologiae Huazhong:81.

Liu Y, Gu S, Zhang Y, Guo Y, and Wang G. 2012. Candidate olfaction genes identified within the Helicoverpa armigera Antennal Transcriptome. PLoS One 7:e48260. 10.1371/journal.pone.0048260

Livak KJ, and Schmittgen TD. 2001. Analysis of relative gene expression data using real-time quantitative PCR and the 2(-Delta Delta C(T)) Method. Methods 25:402-408. 10.1006/meth.2001.1262

Maida R, Ziegelberger G, and Kaissling KE. 2003. Ligand binding to six recombinant pheromone-binding proteins of Antheraea polyphemus and Antheraea pernyi. J Comp Physiol B 173:565-573. 10.1007/s00360-003-0366-4

Mei T, Fu WB, Li B, He ZB, and Chen B. 2018. Comparative genomics of chemosensory protein genes (CSPs) in twenty-two mosquito species (Diptera: Culicidae): Identification, characterization, and evolution. PLoS One 13:e0190412. 10.1371/journal.pone.0190412

Mitchell RF, Hughes DT, Luetje CW, Millar JG, Soriano-Agaton F, Hanks LM, and Robertson HM. 2012. Sequencing and characterizing odorant receptors of the cerambycid beetle Megacyllene caryae. Insect Biochem $\mathrm{Mol}$ Biol 42:499-505. 10.1016/j.ibmb.2012.03.007

Munch D, and Galizia CG. 2016. DoOR 2.0--Comprehensive Mapping of Drosophila melanogaster Odorant Responses. Sci Rep 6:21841. 10.1038/srep21841

Nichols Z, and Vogt RG. 2008. The SNMP/CD36 gene family in Diptera, Hymenoptera and Coleoptera: Drosophila melanogaster, D. pseudoobscura, Anopheles gambiae, Aedes aegypti, Apis mellifera, and Tribolium castaneum. Insect Biochem Mol Biol 38:398-415. 10.1016/j.ibmb.2007.11.003

Olafson PU, Lohmeyer KH, and Dowd SE. 2010. Analysis of expressed sequence tags from a significant livestock pest, the stable fly (Stomoxys calcitrans), identifies transcripts with a putative role in chemosensation and sex determination. Arch Insect Biochem Physiol 74:179-204. 10.1002/arch.20372

Paczkowski S, Maibaum F, Paczkowska M, and Schutz S. 2012. Decaying mouse volatiles perceived by Calliphora vicina Rob.-Desv. J Forensic Sci 57:1497-1506. 10.1111/j.1556-4029.2012.02245.x

Paczkowski S, Nicke S, Ziegenhagen H, and Schutz S. 2015. Volatile emission of decomposing pig carcasses (Sus scrofa domesticus L.) as an indicator for the postmortem interval. J Forensic Sci 60 Suppl 1:S130-137. 10.1111/1556-4029.12638

Pelosi P, Zhou JJ, Ban LP, and Calvello M. 2006. Soluble proteins in insect chemical communication. Cell Mol Life Sci 63:1658-1676. 10.1007/s00018-005-5607-0

Peter J. Clyne CGW, Marc R. Freeman, Derek Lessing, Junhyong Kim, ohn R. Carlson. 1999. A novel family of divergent seven-transmembrane proteins: candidate odorant receptors in Drosophila. Neuron 22:327-328. 10.1016/s0896-6273(00)81093-4

Pitts RJ, Rinker DC, Jones PL, Rokas A, and Zwiebel LJ. 2011. Transcriptome profiling of chemosensory appendages

Peer) reviewing PDF | (2019:12:44386:2:1:NEW 24 Jun 2020) 
643

644

645

646

647

648

649

650

651

652

653

654

655

656

657

658

659

660

661

662

663

664

665

666

667

668

669

670

671

672

673

674

675

676

677

678

679

680

681

682

683 in the malaria vector Anopheles gambiae reveals tissue- and sex-specific signatures of odor coding. BMC Genomics 12:271. 10.1186/1471-2164-12-271

Pophof B. 2004. Pheromone-binding proteins contribute to the activation of olfactory receptor neurons in the silkmoths antheraea polyphemus and Bombyx mori. Chem Senses 29:117-125.

Qiu L, Tao S, He H, Ding W, and Li Y. 2018. Transcriptomics reveal the molecular underpinnings of chemosensory proteins in Chlorops oryzae. BMC Genomics 19:890. 10.1186/s12864-018-5315-4

Rimal S, and Lee Y. 2018. The multidimensional ionotropic receptors of Drosophila melanogaster. Insect Mol Biol 27:1-7. 10.1111/imb.12347

Riveron J, Boto T, and Alcorta E. 2013. Transcriptional basis of the acclimation to high environmental temperature at the olfactory receptor organs of Drosophila melanogaster. BMC Genomics 14:259. 10.1186/1471-216414-259

Rodrigues TB, Dhandapani RK, Duan JJ, and Palli SR. 2017. RNA interference in the Asian Longhorned Beetle:Identification of Key RNAi Genes and Reference Genes for RT-qPCR. Sci Rep 7:8913. 10.1038/s41598-017-08813-1

Rogers ME, Krieger J, and Vogt RG. 2001a. Antennal SNMPs (sensory neuron membrane proteins) of Lepidoptera define a unique family of invertebrate CD36-like proteins. J Neurobiol 49:47-61. 10.1002/neu.1065

Rogers ME, Steinbrecht RA, and Vogt RG. 2001b. Expression of SNMP-1 in olfactory neurons and sensilla of male and female antennae of the silkmoth Antheraea polyphemus. Cell Tissue Res 303:433-446. $10.1007 / \mathrm{s} 004410000305$

Rogers ME, Sun M, Lerner MR, and Vogt RG. 1997. Snmp-1, a novel membrane protein of olfactory neurons of the silk moth Antheraea polyphemus with homology to the CD36 family of membrane proteins. J Biol Chem 272:14792-14799.

Rosier E, Loix S, Develter W, Van de Voorde W, Tytgat J, and Cuypers E. 2016. Time-dependent VOC-profile of decomposed human and animal remains in laboratory environment. Forensic Sci Int 266:164-169. 10.1016/j.forsciint.2016.05.035

Rytz R, Croset V, and Benton R. 2013. Ionotropic receptors (IRs): chemosensory ionotropic glutamate receptors in Drosophila and beyond. Insect Biochem Mol Biol 43:888-897. 10.1016/j.ibmb.2013.02.007

Sato K, Pellegrino M, Nakagawa T, Nakagawa T, Vosshall LB, and Touhara K. 2008. Insect olfactory receptors are heteromeric ligand-gated ion channels. Nature 452:1002-1006. 10.1038/nature06850

Schmittgen TD, and Livak KJ. 2008. Analyzing real-time PCR data by the comparative C(T) method. Nat Protoc 3:1101-1108. 10.1038/nprot.2008.73

Smith DP. 2007. Odor and pheromone detection in Drosophila melanogaster. Pflugers Arch 454:749-758. 10.1007/s00424-006-0190-2

Sukontason K, Sukontason KL, Piangjai S, Boonchu N, Kurahashi H, Hope M, and Olson JK. 2004. Identification of forensically important fly eggs using a potassium permanganate staining technique. Micron 35:391-395. 10.1016/j.micron.2003.12.004

Tomberlin JK, Mohr R, Benbow ME, Tarone AM, and VanLaerhoven S. 2011. A roadmap for bridging basic and applied research in forensic entomology. Annu Rev Entomol 56:401-421. 10.1146/annurev-ento-051710103143

Vieira FG, and Rozas J. 2011. Comparative genomics of the odorant-binding and chemosensory protein gene families across the Arthropoda: origin and evolutionary history of the chemosensory system. Genome Biol

PeerJ reviewing PDF | (2019:12:44386:2:1:NEW 24 Jun 2020) 
684

685

686

687

688

689

690

691

692

693

694

695

696

697

698

699

700

701

702

703

704

705

706

707

708

709

710

711

712

713

714

715

716

717

718

719

720

721

722

723

724

Evol 3:476-490. 10.1093/gbe/evr033

Vogt RG, Miller NE, Litvack R, Fandino RA, Sparks J, Staples J, Friedman R, and Dickens JC. 2009. The insect SNMP gene family. Insect Biochem Mol Biol 39:448-456. 10.1016/j.ibmb.2009.03.007

Vogt RG, and Riddiford LM. 1981. Pheromone binding and inactivation by moth antennae. Nature 293:161-163.

Vosshall LB, Wong AM, and Axel R. 2000. An olfactory sensory map in the fly brain. Cell 102:147-159. 10.1016/s0092-8674(00)00021-0

Wang B, Liu Y, and Wang GR. 2017. Chemosensory genes in the antennal transcriptome of two syrphid species, Episyrphus balteatus and Eupeodes corollae (Diptera: Syrphidae). BMC Genomics 18:586. 10.1186/s12864-017-3939-4

Wang L, Feng Z, Wang X, Wang X, and Zhang X. 2010. DEGseq: an R package for identifying differentially expressed genes from RNA-seq data. Bioinformatics 26:136-138. 10.1093/bioinformatics/btp612

Wang SN, Peng Y, Lu ZY, Dhiloo KH, Zheng Y, Shan S, Li RJ, Zhang YJ, and Guo YY. 2016. Cloning and expression profile of ionotropic receptors in the parasitoid wasp Microplitis mediator (Hymenoptera: Braconidae). J Insect Physiol 90:27-35. 10.1016/j.jinsphys.2016.05.002

Wang Y, Zhang YN, Liu C, Hu GL, Wang M, Yang L, Chu J, and Wang JF. 2018. Development of Aldrichina grahami (Diptera: Calliphoridae) at Constant Temperatures. J Med Entomol 55:1402-1409. 10.1093/jme/tjy128

Wanner KW, Willis LG, Theilmann DA, Isman MB, Feng Q, and Plettner E. 2004. Analysis of the insect os-d-like gene family. J Chem Ecol 30:889-911.

Wicker-Thomas C. 2007. Pheromonal communication involved in courtship behavior in Diptera. J Insect Physiol 53:1089-1100. 10.1016/j.jinsphys.2007.07.003

Yao CA, Ignell R, and Carlson JR. 2005. Chemosensory coding by neurons in the coeloconic sensilla of the Drosophila antenna. J Neurosci 25:8359-8367. 10.1523/JNEUROSCI.2432-05.2005

Yinong Duan WT, Quan Zhou. 2002. Urethral myiasis: a case report. Journal of Nantong University (Medical Sciences) 22:243.

Yuan H, Chang H, Zhao L, Yang C, and Huang Y. 2019. Sex- and tissue-specific transcriptome analyses and expression profiling of olfactory-related genes in Ceracris nigricornis Walker (Orthoptera: Acrididae). BMC Genomics 20:808. 10.1186/s12864-019-6208-x

ZD F. 1992. Key to the common flies of China. Beijing, China: Science publishing house.

Zhang J, Liu Y, Walker WB, Dong SL, and Wang GR. 2015a. Identification and localization of two sensory neuron membrane proteins from Spodoptera litura (Lepidoptera: Noctuidae). Insect Sci 22:399-408. 10.1111/1744-7917.12131

Zhang J, Wang B, Dong S, Cao D, Dong J, Walker WB, Liu Y, and Wang G. 2015b. Antennal transcriptome analysis and comparison of chemosensory gene families in two closely related noctuidae moths, Helicoverpa armigera and H. assulta. PLoS One 10:e0117054. 10.1371/journal.pone.0117054

Zhang T, Gu S, Wu K, Zhang Y, and Guo Y. 2011. Construction and analysis of cDNA libraries from the antennae of male and female cotton bollworms Helicoverpa armigera (Hubner) and expression analysis of putative odorant-binding protein genes. Biochem Biophys Res Commun 407:393-399. 10.1016/j.bbrc.2011.03.032

Zhao Y, Ding J, Zhang Z, Liu F, Zhou C, and Mu W. 2018. Sex- and Tissue-Specific Expression Profiles of Odorant Binding Protein and Chemosensory Protein Genes in Bradysia odoriphaga (Diptera: Sciaridae). Front Physiol 9:107. 10.3389/fphys.2018.00107

Zhou JJ, Vieira FG, He XL, Smadja C, Liu R, Rozas J, and Field LM. 2010. Genome annotation and comparative

Peer) reviewing PDF | (2019:12:44386:2:1:NEW 24 Jun 2020) 
725 analyses of the odorant-binding proteins and chemosensory proteins in the pea aphid Acyrthosiphon

726 pisum. Insect Mol Biol 19 Suppl 2:113-122. 10.1111/j.1365-2583.2009.00919.x

727 Zufall F, and Domingos Al. 2018. The structure of Orco and its impact on our understanding of olfaction. $J$ Gen 728 Physiol 150:1602-1605. 10.1085/jgp.201812226 


\section{Figure 1}

\section{Gene Ontology (GO) classifification analysis of the A.grahami antennal different expression genes.}

Unigenes are classifified into three categories: biological process, cellular component, and molecular function. GO functions are shown on the y-axis. The x-axis shows the number of genes that have a particular GO function.

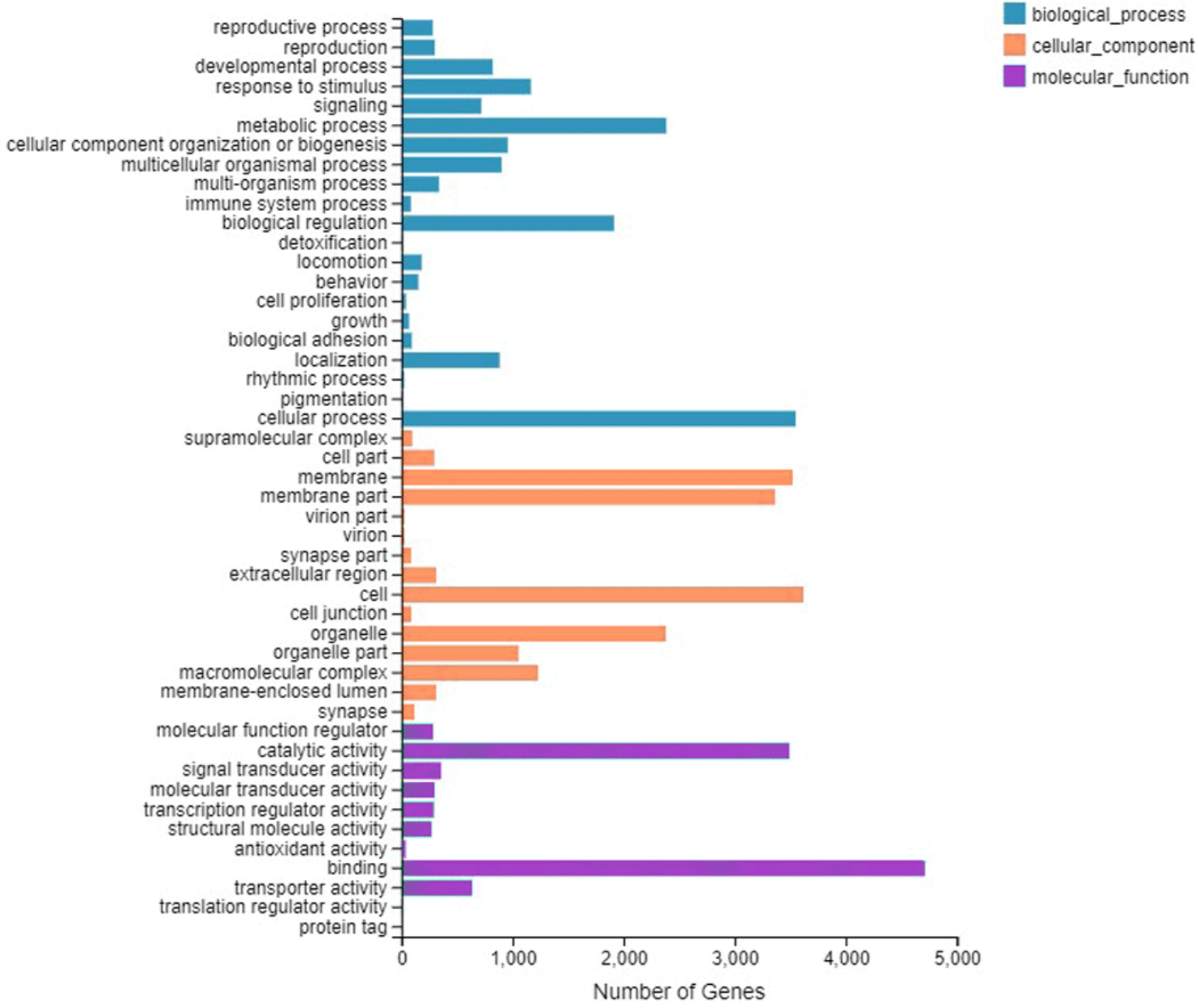


Figure 2

Amino acid alignment of OBPs in A.grahami and OBPs sequences from D. melanogaster .

Amino acid sequences of A.grahami and D. melanogaster OBPs are aligned by DNAMAN. Blue and pink boxes show conserved cysteine.
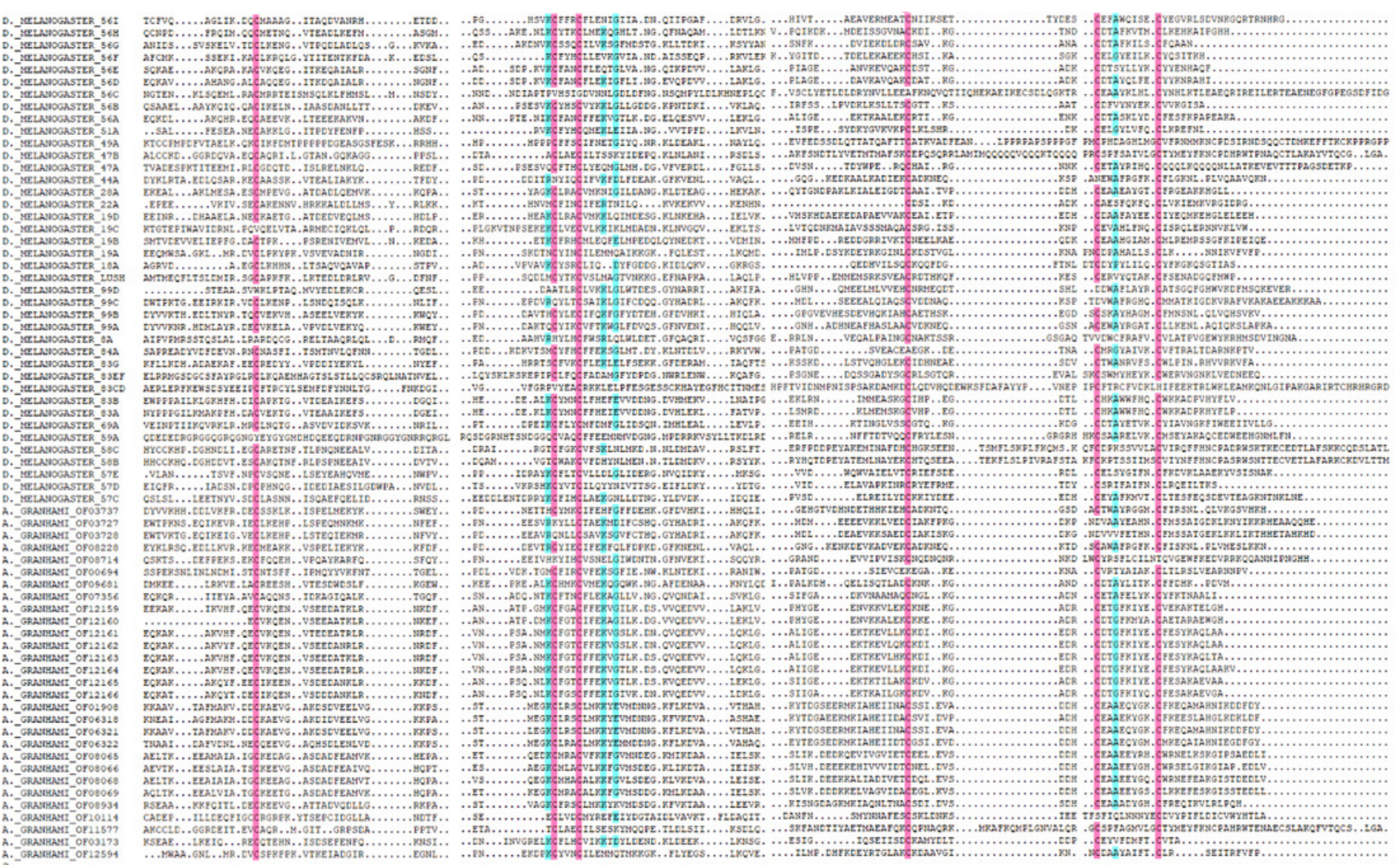
Figure 3

Relative expression levels of $A$.grahami OBPs genes.

(A) A.grahami OF08228. (B) A.grahami OF03173. (C) A.grahami OF08934. FA: female antennae, MA: male antennae, FL: female leg, ML: male leg, FH: female head, MH: male head, FW: female wing, MW: male wing. The error bar represents standard error and the different small letters above each bar indicate significant differences in transcript abundances $(p<0.05)$.
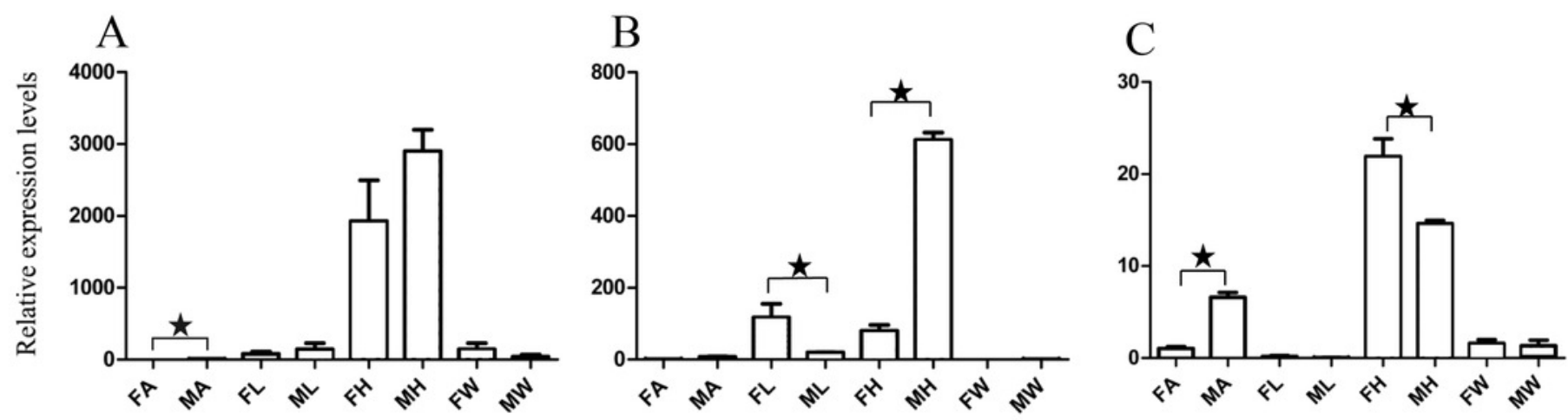
Figure 4

Relative expression levels of A.grahami ORs genes.

(A) A.grahami OF05347. (B) A.grahami OF11636. (C) A.grahami OF03270. (D) A.grahami

BGI_novel_G000488. (E) A.grahami OF12341. (F) A.grahami OF03271. FA: female antennae, MA: male antennae, FL: female leg, ML: male leg, FH: female head, MH: male head, FW:

female wing, MW: male wing. The error bar represents standard error and the different small letters above each bar indicate significant differences in transcript abundances $(p<0.05)$.
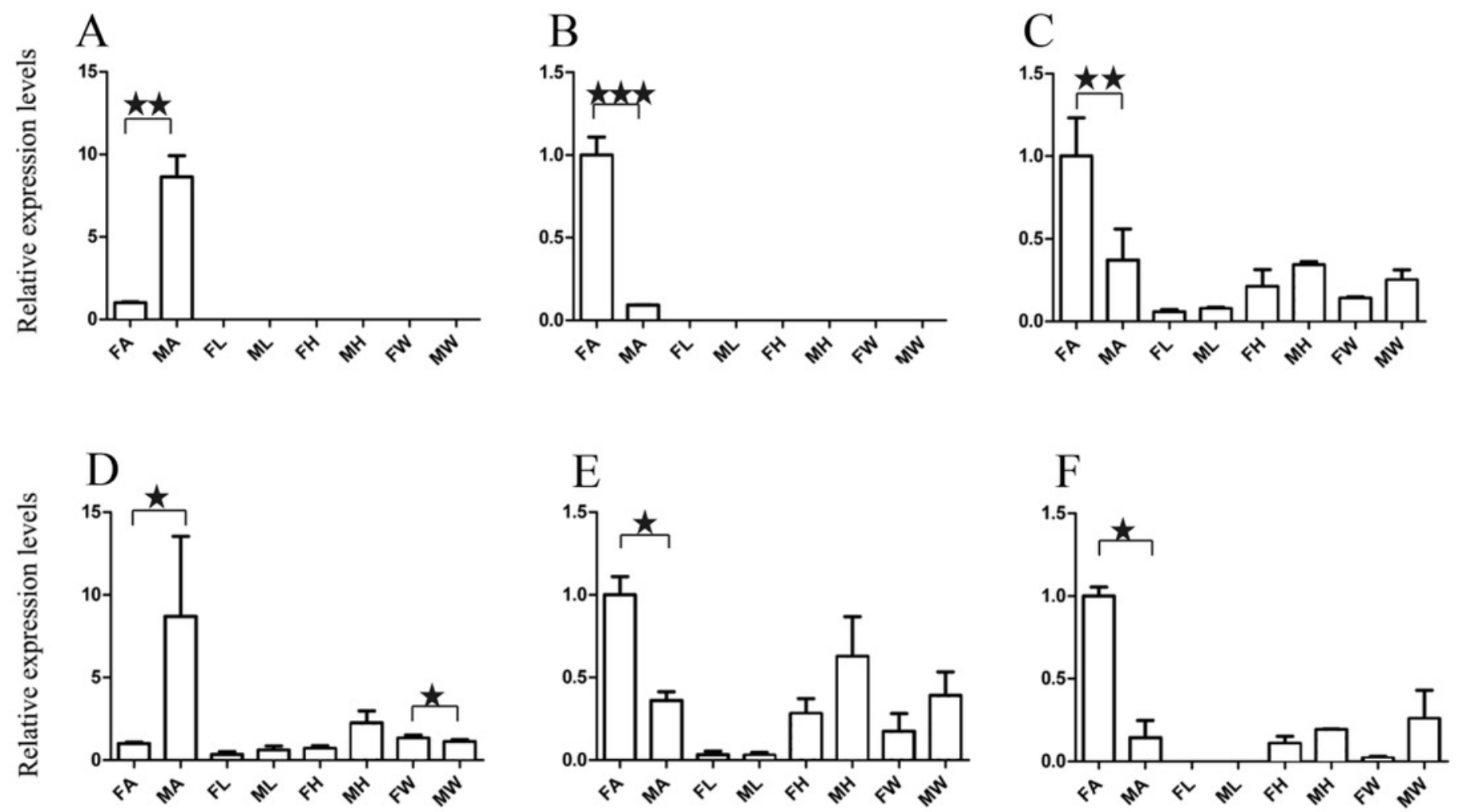


\section{Figure 5}

Relative expression levels of A.grahami non-Olfactory genes.

(A) A.grahami OF12624. (B) A.grahami OF04198. (C) A.grahami BGI_novel_G000012. (D)

A.grahami BGI_novel_G000010. FA: female antennae, MA: male antennae, FL: female leg, ML:

male leg, FH: female head, MH: male head, FW: female wing, MW: male wing. The error bar represents standard error and the different small letters above each bar indicate significant differences in transcript abundances $(p<0.05)$. 


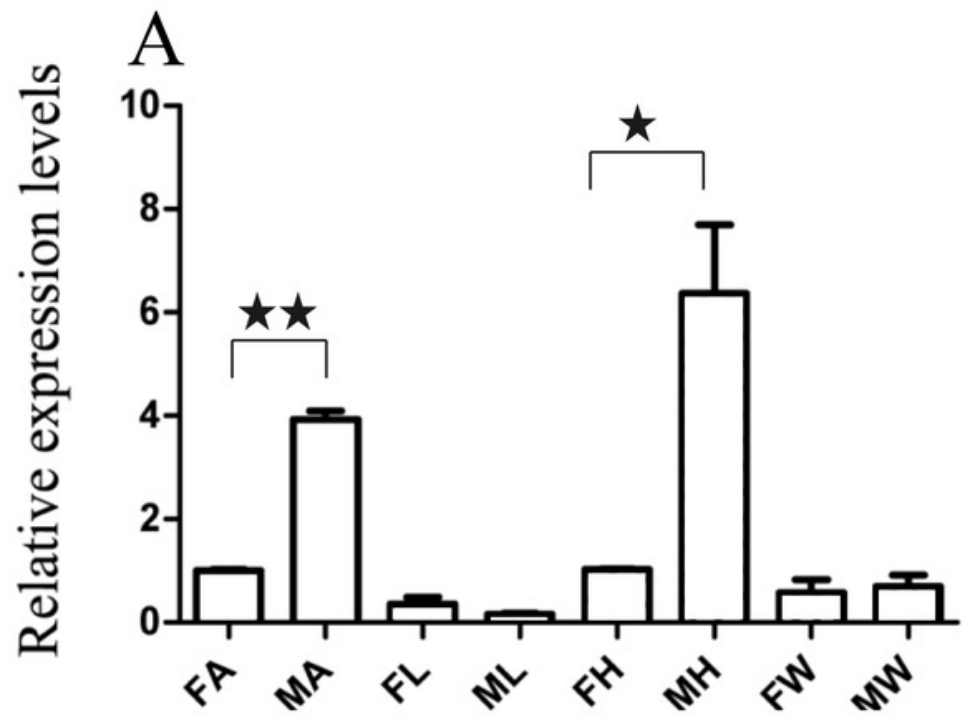

B
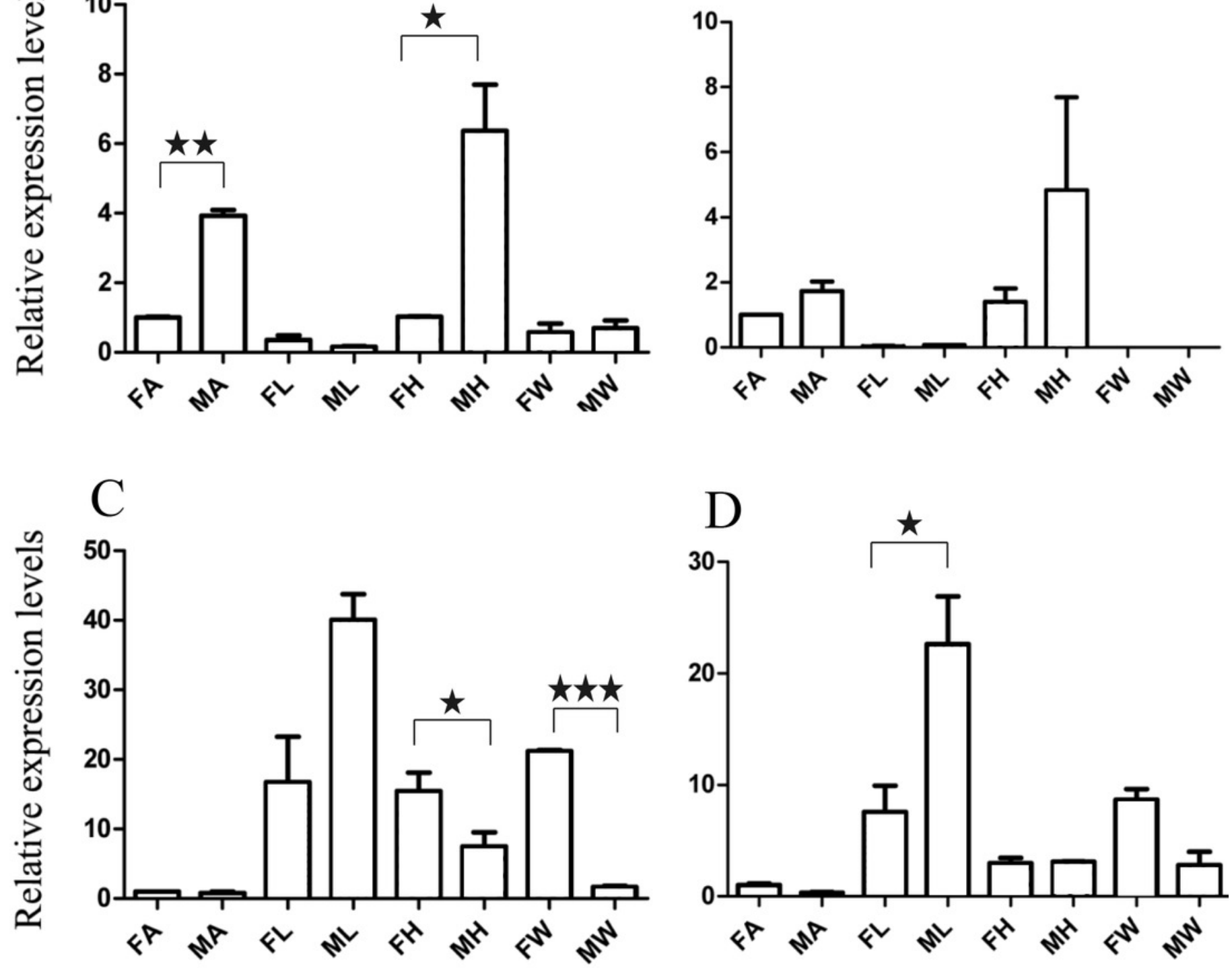
Figure 6

Phylogenetic tree of putative OBPs from A.grahami and other insects.

D. melanogaster: Drosophila melanogaster $\square s k y$-blue ; C. stygia : Calliphora stygia (lake blue) ; M. domestica: Musca domestica (purple); L. cuprina: Lucilia cuprina (yellow); A.grahami: Aldrichina grahami (black) . 


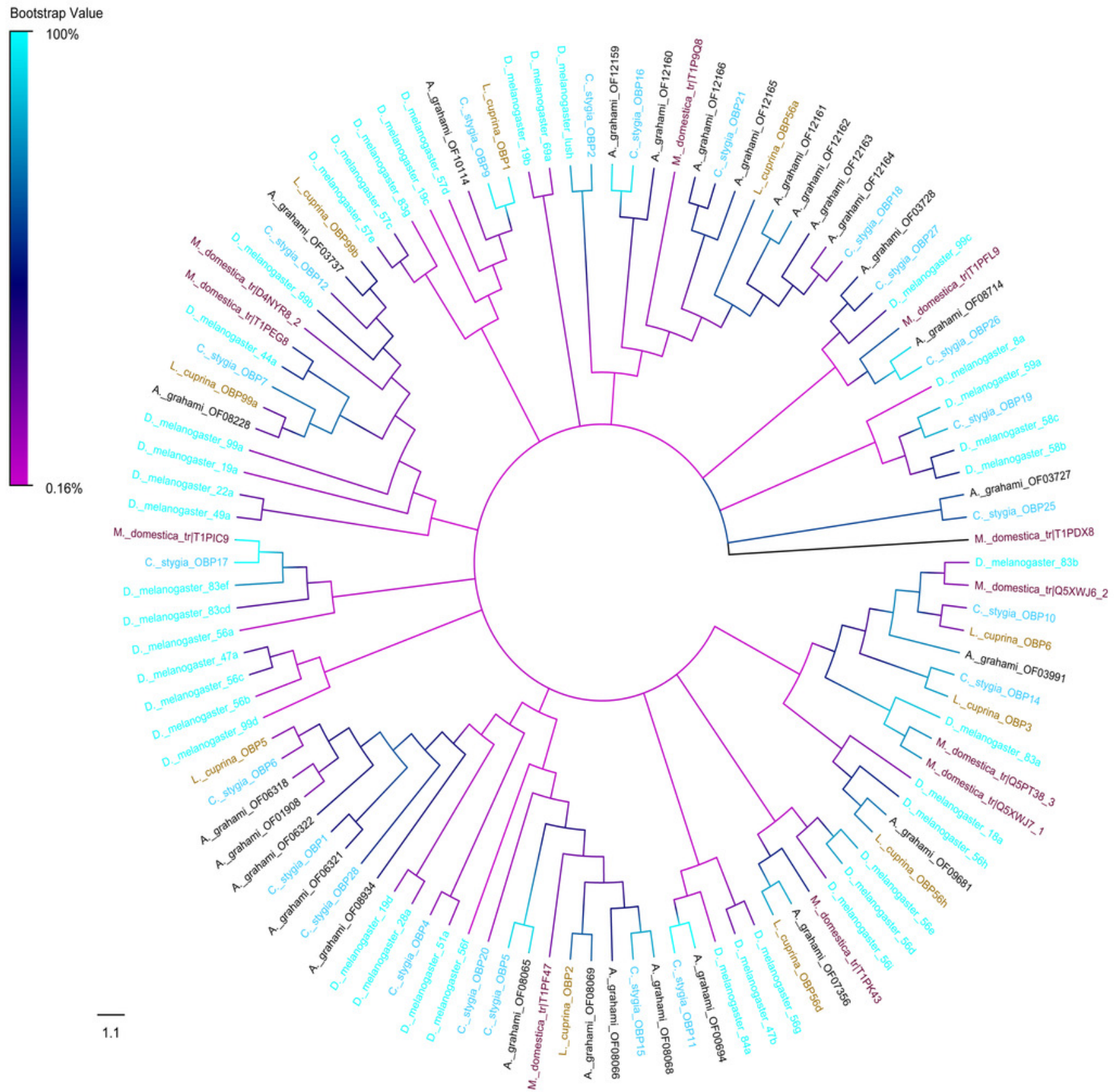




\section{Figure 7}

Phylogenetic tree of putative ORs from A.grahami and other insects.

D. melanogaster: Drosophila melanogaster $\square s k y$-blue ; C. stygia : Calliphora stygia (lake blue) ; M. domestica: Musca domestica (purple); L. cuprina: Lucilia cuprina (yellow); A.grahami: Aldrichina grahami(black) . 


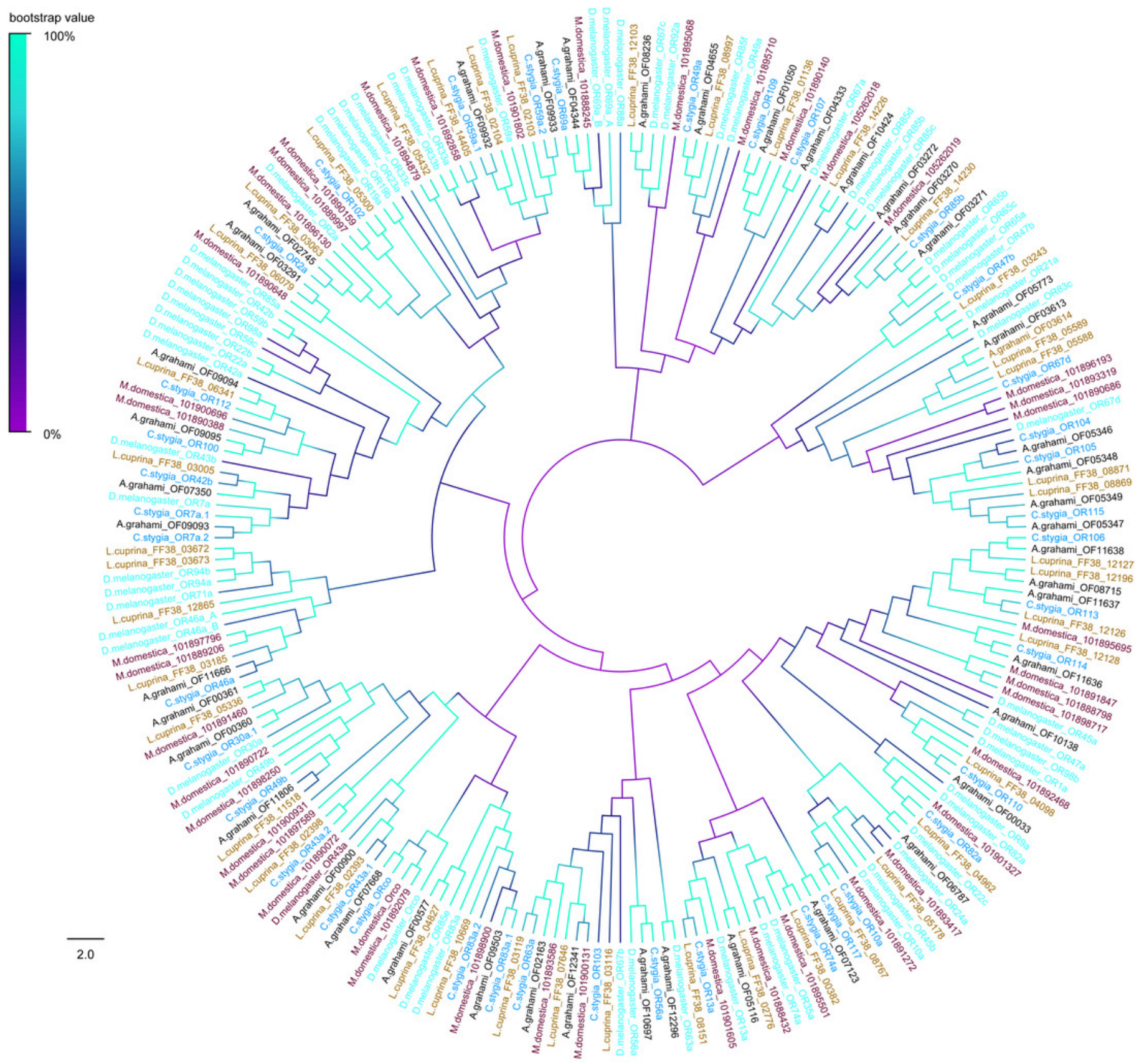




\section{Table $\mathbf{1}$ (on next page)}

Unigenes of candidate odorant binding proteins in A.grahami

ORF: opening read frame.

FPKM: Fragments per kilobase of transcript per million mapped reads 
1 Table1: Unigenes of candidate odorant binding proteins in A.grahami

\begin{tabular}{|c|c|c|c|c|c|c|c|c|c|c|c|c|c|}
\hline Gene name & $\begin{array}{l}\text { Length } \\
\text { (nt) }\end{array}$ & $\begin{array}{l}\text { ORF } \\
\text { (aa) }\end{array}$ & Status & $\begin{array}{l}\text { Signal } \\
\text { Peptide }\end{array}$ & E-value & Best Blastp hit & Domains & $\begin{array}{l}\text { Superfa } \\
\text { mily }\end{array}$ & $\begin{array}{l}\text { Aldrich F1 } \\
\text { FPKM }\end{array}$ & $\begin{array}{l}\text { Aldrich F2 } \\
\text { FPKM }\end{array}$ & $\begin{array}{l}\text { Aldrich F3 } \\
\text { FPKM }\end{array}$ & $\begin{array}{l}\text { Aldrich M1 } \\
\text { FPKM }\end{array}$ & $\begin{array}{l}\text { Aldrich M2 } \\
\text { FPKM }\end{array}$ \\
\hline OF00694 & 5063 & 171 & complete & $\mathrm{Y}$ & $2 \mathrm{E}-108$ & AID61304.1|odorant binding protein [Calliphora stygia] & $\mathrm{PhBP}$ & cl11600 & 6793.97 & 6491.5 & 6538.27 & 7557.2 & 7495.94 \\
\hline OF01908 & 1908 & 148 & complete & $\mathrm{Y}$ & 1E-96 & AID61299.1 |odorant binding protein [Calliphora stygia] & $\mathrm{PhBP}$ & cl11600 & 4.55 & 1.15 & 2.66 & 0.84 & 1.79 \\
\hline OF03173 & 336 & 107 & $\mathrm{~N}$ & $\mathrm{~N}$ & $3 \mathrm{E}-12$ & XP_005189169.1|PREDICTED: general odorant-binding protein 57c-like [Musca domestica] & $\mathrm{PhBP}$ & cl1 1600 & 0 & 0 & 0 & 0 & 0.41 \\
\hline OF03727 & 528 & 150 & complete & $\mathrm{Y}$ & $3 \mathrm{E}-102$ & AID61318.1 |odorant binding protein [Calliphora stygia] & PBP GO & cll1600 & 449.22 & 330.2 & 451.67 & 622.38 & 425.39 \\
\hline OF03728 & 542 & 150 & complete & $\mathrm{Y}$ & $1 \mathrm{E}-78$ & AID61320.1|odorant binding protein [Calliphora stygia] & PBP_GO & cll1600 & 7.63 & 5.37 & 3.25 & 17.5 & 5.01 \\
\hline OF03737 & 572 & 163 & complete & $\mathrm{Y}$ & $3 \mathrm{E}-93$ & AID61305.1|odorant binding protein [Calliphora stygia] & PBP_GO & cl1 1600 & 109.56 & 102.35 & 176.49 & 225.97 & 64.39 \\
\hline OF03989 & 5496 & 144 & $\mathrm{~N}$ & $\mathrm{~N}$ & 7E-86 & KNC25071.1|Pheromone-binding protein-related protein 3 [Lucilia cuprina] & $\mathrm{PhBP}$ & cl11600 & 5731.45 & 5449.59 & 7028.92 & 5625.04 & 6036.15 \\
\hline OF03991 & 1523 & 152 & $\mathrm{~N}$ & $\mathrm{Y}$ & $9 \mathrm{E}-105$ & AID61303.1|odorant binding protein [Calliphora stygia] & PBP_GO & cll1600 & 2996.22 & 2605.5 & 3211.17 & 3989.71 & 3439.09 \\
\hline OF04509 & 743 & 200 & $\mathrm{~N}$ & $\mathrm{~N}$ & $4 \mathrm{E}-84$ & AID61317.1|odorant binding protein, partial [Calliphora stygia] & - & - & 1.48 & 2.48 & 1.9 & 2.75 & 3.12 \\
\hline OF06318 & 708 & 148 & complete & $\mathrm{Y}$ & 4E-91 & XP_023303590.1|general odorant-binding protein 28a-like [Lucilia cupr & $\mathrm{PhBP}$ & cl11600 & 3.25 & 0.68 & 3.97 & 2.3 & 1.05 \\
\hline OF06321 & 1883 & 148 & complete & $\mathrm{Y}$ & $6 \mathrm{E}-97$ & AID61299.1|odorant binding protein [Calliphora stygia] & $\mathrm{PhBP}$ & cl1 1600 & 2.15 & 1.96 & 0.83 & 0.75 & 0 \\
\hline OF06322 & 607 & 148 & complete & $\mathrm{Y}$ & 1E-71 & AID61299.1 |odorant binding protein [Calliphora stygia] & PBP GO & cl11600 & 16.29 & 18.22 & 14.52 & 15.05 & 16.09 \\
\hline OF07356 & 538 & 135 & complete & $\mathrm{Y}$ & $1 \mathrm{E}-83$ & AID61306.1|odorant binding protein, partial [Calliphora stygia] & PBP_GO & cll1600 & 0.2 & 0.21 & 0 & 0.2 & 0.22 \\
\hline OF08065 & 741 & 143 & complete & $\mathrm{Y}$ & $1 \mathrm{E}-76$ & AID61298.1|odorant binding protein [Calliphora stygia] & $\mathrm{PBP}_{-}^{-} \mathrm{GO}$ & cl11600 & 11111.59 & 10312.81 & 12733.79 & 12913.21 & 10822.75 \\
\hline OF08070 & 865 & 111 & $\mathrm{~N}$ & $\mathrm{Y}$ & 7E-62 & XP_023299671.1|general odorant-binding protein 19d-like [Lucilia cuprina] & $\mathrm{PBP}_{-}^{-} \mathrm{GO}$ & & 3.67 & 2.67 & 2.48 & 4.19 & 2.05 \\
\hline OF08228 & 1720 & 141 & complete & $\mathrm{Y}$ & $2 \mathrm{E}-93$ & AID61300.1|odorant binding protein [Calliphora stygia] & PBP_GO & cll1600 & 6.71 & 9.04 & 6.23 & 82.13 & 10.14 \\
\hline OF08714 & 540 & 153 & complete & $\mathrm{Y}$ & 5E-99 & AID61319.1 lodorant binding protein, partial [Calliphora stygia] & $\mathrm{PBP}^{-} \mathrm{GO}$ & cl11600 & 284.68 & 298.87 & 337.26 & 231.69 & 180.27 \\
\hline OF08934 & 592 & 147 & complete & $\mathrm{Y}$ & $2 \mathrm{E}-63$ & KNC27005.1|Pheromone-binding protein-related protein 5 [Lucilia cuprina] & $\mathrm{PhBP}$ & cl11600 & 0 & 0 & 0 & 0.18 & 0 \\
\hline OF11577 & 3511 & 189 & complete & $\mathrm{Y}$ & $2 \mathrm{E}-129$ & AID61316.1|odorant binding protein [Calliphora stygia] & - & - & 1.73 & 1.16 & 0.28 & 1.86 & 2.89 \\
\hline OF12159 & 476 & 135 & complete & $\mathrm{Y}$ & $1 \mathrm{E}-88$ & AID61309.1 odorant binding protein [Calliphora stygia] & PBP GO & cl11600 & 57.97 & 29.38 & 33.06 & 206.02 & 63.39 \\
\hline OF12160 & 478 & 118 & complete & $\mathrm{Y}$ & $9 \mathrm{E}-62$ & AID61309.1 |odorant binding protein [Calliphora stygia] & PBP_GO & cl1 1600 & 2224.07 & 1490.12 & 1146.79 & 3112.62 & 1741.97 \\
\hline OF12161 & 540 & 136 & complete & $\mathrm{Y}$ & $4 \mathrm{E}-82$ & XP_023297832.1|general odorant-binding protein 56a-like [Lucilia c & PBP_GO & cll1600 & 0 & 0.21 & 0 & 0 & 0.22 \\
\hline OF12162 & 484 & 136 & complete & $\mathrm{Y}$ & $3 \mathrm{E}-79$ & XP_023297815.1|general odorant-binding protein 56a-like [Lucilia cuprina] & $\mathrm{PBP}^{-} \mathrm{GO}$ & cll1600 & 0 & 0 & 0 & 0.23 & 0 \\
\hline OF12163 & 484 & 136 & complete & $\mathrm{Y}$ & $4 \mathrm{E}-82$ & XP_023297832.1|general odorant-binding protein 56a-like [Lucilia cuprina] & PBP_GO & cll1600 & 0 & 0 & 0 & 0.23 & 0 \\
\hline OF12164 & 523 & 138 & complete & $\mathrm{Y}$ & $8 \mathrm{E}-84$ & XP_023297815.1|general odorant-binding protein 56a-like [Lucilia cuprina] & PBP_GO & D.cl11600 & 0 & 0 & 0 & 0.21 & 0 \\
\hline OF12165 & 518 & 136 & complete & $\mathrm{Y}$ & $8 \mathrm{E}-79$ & AID61314.1|odorant binding protein, partial [Calliphora stygia] & $\mathrm{PBP}^{-} \mathrm{GO}$ & cl11600 & 17.14 & 4.38 & 4.86 & 16.54 & 6.3 \\
\hline OF12166 & 507 & 134 & complete & $\mathrm{Y}$ & $6 \mathrm{E}-72$ & AID61314.1|odorant binding protein, partial [Calliphora stygia] & PBP_GO & cl1 1600 & 6.88 & 0.6 & 1.46 & 1.43 & 0.31 \\
\hline OF12594 & 430 & 116 & complete & $\mathrm{N}$ & $3 \mathrm{E}-80$ & AID61296.1 lodorant binding protein [Calliphora stygia] & $\mathrm{PBP}^{-} \mathrm{GO}$ & cl11600 & 7264.31 & 7580.12 & 9447.39 & 6675.22 & 5594.38 \\
\hline OF06267 & 691 & 207 & $\mathrm{~N}$ & $\mathrm{Y}$ & $5 \mathrm{E}-106$ & XP_023306331.1|putative odorant-binding protein A5 [Lucilia cuprina] & PEBP_el & ucl00227 & 4579.82 & 3726.1 & 4497.4 & 7292.1 & 7843.41 \\
\hline OF08890 & 530 & 146 & $\mathrm{~N}$ & $\mathrm{Y}$ & $8 \mathrm{E}-102$ & AID61325.1|chemosensory protein [Calliphora stygia] & OS-D & c104042 & 53230.86 & 42911.58 & 55432.39 & 46095.65 & 51606.36 \\
\hline OF11575 & 968 & 295 & $\mathrm{~N}$ & $\mathrm{~N}$ & $2 \mathrm{E}-81$ & XP_023301477.1|general odorant-binding protein 71 [Lucilia cuprina] & - & - & 201.94 & 299.18 & 244.47 & 286.73 & 303.85 \\
\hline OF09681 & 27357 & 139 & complete & $\mathrm{Y}$ & $3 \mathrm{E}-50$ & AID61301.1|odorant binding protein [Calliphora stygia] & PBP_GO & cll1600 & 2.91 & 2.3 & 3.79 & 11.58 & 15.05 \\
\hline OF08066 & 709 & 143 & complete & $\mathrm{Y}$ & $4 \mathrm{E}-64$ & AID61308.1 |odorant binding protein [Calliphora stygia] & $\mathrm{PBP}_{\mathrm{GO}}^{-}$ & cl11600 & 23.69 & 27.51 & 50.12 & 46.85 & 52.39 \\
\hline OF08068 & 7857 & 143 & complete & $\mathrm{Y}$ & $1 \mathrm{E}-87$ & AID61308.1 |odorant binding protein [Calliphora stygia] & PBP_GO & cl11600 & 0 & 0 & 0 & 0 & 0.01 \\
\hline OF08069 & 4971 & 143 & complete & $\mathrm{Y}$ & $4 \mathrm{E}-74$ & KNC26975.1|Pheromone-binding protein-related protein 2 [Luci & PBP_GO & cl11600 & 37 & 3317 & 375 & 438 & 3998.67 \\
\hline OF10114 & 705 & 177 & complete & $\mathrm{Y}$ & $2 \mathrm{E}-74$ & KNC33289.1 |hypothetical protein FF38 06045, partial [Lucilia cuprina] & - & - & 0 & 0.3 & 0 & 0 & 0 \\
\hline
\end{tabular}

3 ORF: opening read frame.

4 FPKM: Fragments per kilobase of transcript per million mapped reads 
Table 2 (on next page)

Unigenes of odorant recpetors proteins in A.grahami

TMDs: Transmembrane domains FPKM: Fragments per kilobase of transcript per million mapped reads 


\section{Table 2: Unigenes of odorant recpetors proteins in A.grahami}

\begin{tabular}{|c|c|c|c|c|c|c|c|c|c|c|c|c|c|}
\hline \multirow{3}{*}{$\begin{array}{l}\text { Gene } \\
\text { name }\end{array}$} & \multirow{3}{*}{$\begin{array}{l}\text { Lengt } \\
\mathrm{h} \\
\text { (nt) }\end{array}$} & \multirow{3}{*}{$\begin{array}{l}\text { Amino } \\
\text { acid } \\
\text { length } \\
\text { (aa) }\end{array}$} & \multirow{3}{*}{ TMDs } & \multirow{3}{*}{ s Evalue } & \multirow{3}{*}{ BLASTx best hit } & \multirow{3}{*}{ Domains } & \multirow{3}{*}{ superfamily } & \multirow{2}{*}{$\begin{array}{l}\text { Aldrich } \\
\text { F1 }\end{array}$} & \multirow{2}{*}{$\begin{array}{l}\text { Aldrich } \\
\text { F2 }\end{array}$} & \multirow{2}{*}{$\begin{array}{l}\text { Aldrich } \\
\text { F3 }\end{array}$} & \multirow{2}{*}{$\begin{array}{l}\text { Aldrich } \\
\text { M1 }\end{array}$} & \multirow{2}{*}{$\begin{array}{l}\text { Aldrich } \\
\text { M2 }\end{array}$} & \multirow{2}{*}{$\begin{array}{l}\text { Aldrich } \\
\text { M3 }\end{array}$} \\
\hline & & & & & & & & & & & & & \\
\hline & & & & & & & & FPKM & FPKM & FPKM & FPKM & FPKM & FPKM \\
\hline OF0003 & 31355 & 370 & 6 & 0 & $\begin{array}{l}\text { AID61240.1 |odorant receptor, partial } \\
\text { [Calliphora stygia] }\end{array}$ & $\begin{array}{l}7 \mathrm{tm} \_6 \\
\text { superfamily }\end{array}$ & & 6.91 & 4.42 & 7.13 & 6.71 & 9.53 & 8.73 \\
\hline OF0329 & 122874 & 662 & 8 & $\begin{array}{l}3.00 \mathrm{E}- \\
170\end{array}$ & $\begin{array}{l}\underline{\mathrm{XP}} \text { } 023303346.1 \text { odorant receptor } 7 \mathrm{a}- \\
\underline{\text { like [Lucilia cuprina] }}\end{array}$ & $7 \mathrm{tm} \_6$ & $\mathrm{cl} 20237$ & 2.03 & 2.07 & 2.12 & 1.09 & 1.43 & 1.6 \\
\hline OF0909 & 26367 & 750 & 12 & 0 & $\begin{array}{l}\text { KNC26770.1 putative odorant receptor } \\
\underline{\text { 7a }[\text { Lucilia cuprina] }}\end{array}$ & $7 \mathrm{tm} \_6$ & $\operatorname{cl} 20237$ & 80.79 & 60.23 & 73.3 & 44.91 & 33.22 & 31.48 \\
\hline OF0909 & 310862 & 430 & 4 & 0 & $\begin{array}{l}\text { AID61204.1|odorant receptor, partial } \\
\text { [Calliphora stygia] }\end{array}$ & $7 \mathrm{tm} \_6$ & $\operatorname{cl} 20237$ & 0.2 & 0.23 & 0.13 & 0.15 & 0.17 & 0.1 \\
\hline OF0909 & 41419 & 407 & 6 & 0 & $\begin{array}{l}\text { XP_023291420.1 } \text { odorant receptor 42b- } \\
\text { like [Lucilia cuprina] }\end{array}$ & $7 \mathrm{tm} \_6$ & $\operatorname{cl} 20237$ & 0.06 & 0.13 & 0.13 & 0.07 & 0.35 & 0 \\
\hline OF0909 & 53759 & 433 & 7 & 0 & $\begin{array}{l}\text { AID61230.1 odorant receptor } \\
\text { [Calliphora stygia] }\end{array}$ & $7 \mathrm{tm} \_6$ & $\operatorname{cl} 20237$ & 93.55 & 66.21 & 86.56 & 117.23 & 135.59 & 75.1 \\
\hline OF0216 & 35901 & 431 & 6 & 0 & $\begin{array}{l}\text { AID61219.1|odorant receptor, partial } \\
\text { CCalliphora stygia] }\end{array}$ & $\begin{array}{l}7 \mathrm{tm} \_6 \\
\text { superfamily }\end{array}$ & - & 15.19 & 11.05 & 11.37 & 25.03 & 28.1 & 21.15 \\
\hline OF0216 & 45239 & 271 & 4 & $6.00 \mathrm{E}-$ & $\underline{\text { XP } 023305776.1 \text { odorant receptor } 63 \mathrm{a}-}$ & $7 \mathrm{tm} \_6$ & - & 21.83 & 21.73 & 21.82 & 32.99 & 38.56 & 33.01 \\
\hline
\end{tabular}




\begin{tabular}{|c|c|c|c|c|c|c|c|c|c|c|c|c|}
\hline & & & 159 & $\underline{\text { like [Lucilia cuprina] }}$ & superfamily & & & & & & & \\
\hline OF12341 9653 & 432 & 7 & 0 & $\begin{array}{l}\text { XP } 023306197.1 \text { odorant receptor 63a- } \\
\underline{\text { like [Lucilia cuprina] }}\end{array}$ & $\begin{array}{l}7 \mathrm{tm} \_6 \\
\text { superfamily }\end{array}$ & - & 0 & 0.02 & 0 & 0 & 0 & 0 \\
\hline OF122965257 & 489 & 6 & 0 & $\begin{array}{l}\text { AID61256.1|gustatory receptor } \\
\text { [Calliphora stygia] }\end{array}$ & $7 \mathrm{tm}_{-} 7$ & cl19976 & 17.78 & 11.27 & 17.35 & 17.55 & 26.16 & 16.81 \\
\hline OF12237 1011 & 314 & 5 & 0 & $\begin{array}{l}\text { AID61205.1|odorant receptor, partial } \\
\text { [Calliphora stygia] }\end{array}$ & $\begin{array}{l}7 \mathrm{tm} \_6 \\
\text { superfamily }\end{array}$ & - & 21.96 & 22.55 & 22.87 & 19.26 & 32.51 & 28.36 \\
\hline OF051169171 & 441 & 4 & 0 & $\begin{array}{l}\text { KNC34511.1 putative odorant receptor } \\
\underline{\text { 13a [Lucilia cuprina] }}\end{array}$ & $\begin{array}{l}7 \mathrm{tm} \_6 \\
\text { superfamily }\end{array}$ & - & 0.02 & 0.01 & 0.02 & 0 & 0 & 0.01 \\
\hline OF08895 1732 & 434 & 2 & 0 & $\begin{array}{l}\underline{\text { XP } 023299035.1 \text { odorant receptor 13a }} \\
\text { [Lucilia cuprina] }\end{array}$ & $\begin{array}{l}7 \mathrm{tm}_{-} 6 \\
\text { superfamily }\end{array}$ & - & 6.41 & 4.22 & 5.83 & 14.64 & 8.2 & 6.38 \\
\hline OF04344 21164 & 425 & 6 & 0 & $\begin{array}{l}\text { AID61222.1|odorant receptor } \\
\text { [Calliphora stygia] }\end{array}$ & $\begin{array}{l}7 \mathrm{tm} \_6 \\
\text { superfamily }\end{array}$ & - & 17.3 & 14.93 & 11.93 & 18.02 & 17.93 & 12.12 \\
\hline OF03613 1357 & 364 & 4 & 0 & $\begin{array}{l}\text { XP_023294606.1|odorant receptor 67d- } \\
\text { like [Lucilia cuprina] }\end{array}$ & $\begin{array}{l}7 \mathrm{tm} \_6 \\
\text { superfamily }\end{array}$ & - & 41.35 & 34.72 & 41.71 & 51.6 & 67.66 & 59.32 \\
\hline OF03614 1694 & 389 & 4 & 0 & $\begin{array}{l}\text { XP_023294606.1 odorant receptor 67d- } \\
\text { like [Lucilia cuprina] }\end{array}$ & $\begin{array}{l}7 \mathrm{tm} \_6 \\
\text { superfamily }\end{array}$ & - & 23.77 & 20.69 & 24.16 & 34.77 & 42.81 & 29.3 \\
\hline OF05346 1378 & 389 & 4 & 0 & $\begin{array}{l}\text { AID61234.1|odorant receptor, partial } \\
\text { [Calliphora stygia] }\end{array}$ & $\begin{array}{l}7 \mathrm{tm} \_6 \\
\text { superfamily }\end{array}$ & - & 6.29 & 5.63 & 5.55 & 7.44 & 8.26 & 5.33 \\
\hline
\end{tabular}




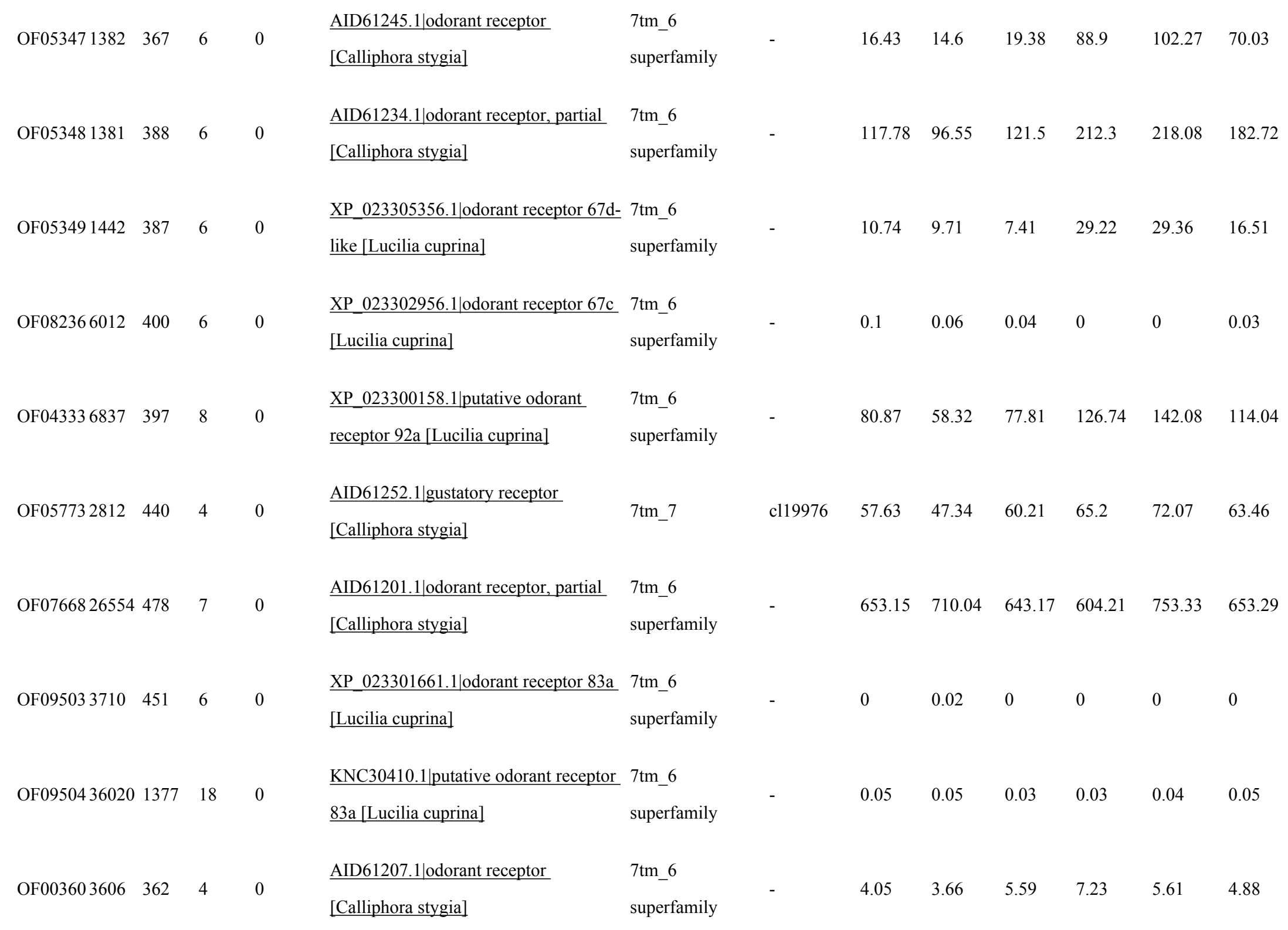




\begin{tabular}{|c|c|c|c|c|c|c|c|c|c|c|c|c|}
\hline OF00361 1460 & 359 & 4 & 0 & $\begin{array}{l}\text { XP_023295767.1 lodorant receptor 30a- } \\
\underline{\text { like [Lucilia cuprina] }}\end{array}$ & $7 \mathrm{tm} \_6$ & $\operatorname{cl} 20237$ & 18.1 & 14.39 & 17.19 & 39.55 & 35.98 & 21.95 \\
\hline OF03270 6328 & 431 & 4 & 0 & $\begin{array}{l}\text { KNC22013.1 putative odorant receptor } \\
\underline{85 \mathrm{~b} \text { [Lucilia cuprina] }}\end{array}$ & $7 \mathrm{tm} \_6$ & $\operatorname{cl} 20237$ & 0.64 & 0.46 & 0.49 & 0.1 & 0.03 & 0.09 \\
\hline OF03271 1412 & 406 & 3 & 0 & $\begin{array}{l}\text { XP_023301736.1 } \text { odorant receptor 85b- } \\
\underline{\text { like [Lucilia cuprina] }}\end{array}$ & $7 \mathrm{tm} \_6$ & cl20237 & 0.19 & 0.67 & 0.85 & 0 & 0 & 0.07 \\
\hline OF03272 8161 & 430 & 4 & 0 & $\begin{array}{l}\text { KNC22013.1 putative odorant receptor } \\
\underline{85 \mathrm{~b} \text { [Lucilia cuprina] }}\end{array}$ & $7 \mathrm{tm} \_6$ & cl20237 & 0 & 0 & 0.02 & 0.01 & 0 & 0 \\
\hline OF104242968 & 397 & 6 & 0 & $\begin{array}{l}\text { XP_023303249.1|putative odorant } \\
\underline{\text { receptor 85d [Lucilia cuprina] }}\end{array}$ & $7 \mathrm{tm} \_6$ & cl20237 & 0.09 & 0 & 0.12 & 0.03 & 0.06 & 0.09 \\
\hline OF04655 1425 & 409 & 4 & 0 & $\begin{array}{l}\text { AID61214.1|odorant receptor, partial } \\
\text { [Calliphora stygia] }\end{array}$ & $\begin{array}{l}7 \mathrm{tm}_{-} 6 \\
\text { superfamily }\end{array}$ & - & 63.51 & 54.65 & 62.79 & 152.99 & 153.77 & 119.31 \\
\hline OF010501401 & 401 & 6 & 0 & $\begin{array}{l}\text { AID61239.1 odorant receptor } \\
\text { [Calliphora stygia] }\end{array}$ & $\begin{array}{l}7 \mathrm{tm}_{-} 6 \\
\text { superfamily }\end{array}$ & - & 201.87 & 159.01 & 201.63 & 169.82 & 156.98 & 116.52 \\
\hline OF073503826 & 400 & 6 & 0 & $\begin{array}{l}\text { AID61209.1 lodorant receptor } \\
\text { [Calliphora stygia] }\end{array}$ & $7 \mathrm{tm} \_6$ & cl20237 & 553.8 & 565.58 & 537.74 & 370.78 & 541.56 & 439.42 \\
\hline OF10697 6210 & 382 & 6 & 0 & $\begin{array}{l}\text { TMW44128.1/hypothetical protein } \\
\text { DOY81 } 010793 \text { [Sarcophaga bullata] }\end{array}$ & $\begin{array}{l}7 \mathrm{tm} \_6 \\
\text { superfamily }\end{array}$ & - & 16.45 & 16.59 & 16.2 & 8.39 & 13.07 & 11.52 \\
\hline
\end{tabular}




\begin{tabular}{|c|c|c|c|c|c|c|c|c|c|c|c|c|}
\hline OF08715 18470 & 388 & 6 & 0 & $\begin{array}{l}\text { XP_023292635.1 } \mid \text { odorant receptor } 45 \mathrm{a}- \\
\text { like [Lucilia cuprina] }\end{array}$ & $\begin{array}{l}7 \mathrm{tm} \_6 \\
\text { superfamily }\end{array}$ & - & 0.02 & 0.03 & 0.04 & 0.03 & 0.03 & 0.03 \\
\hline OF10138 1444 & 400 & 7 & 4.00E-92 & $\begin{array}{l}\text { KNC21829.1 putative odorant receptor } \\
\underline{45 \mathrm{a}[\text { Lucilia cuprina] }}\end{array}$ & $\begin{array}{l}7 \mathrm{tm} \_6 \\
\text { superfamily }\end{array}$ & - & 0 & 0.07 & 0 & 0 & 0 & 0.06 \\
\hline OF116363805 & 418 & 7 & 0 & $\begin{array}{l}\text { AID61244.1 lodorant receptor } \\
\text { Calliphora stygia] }\end{array}$ & $\begin{array}{l}7 \mathrm{tm} \_6 \\
\text { superfamily }\end{array}$ & - & 6.47 & 5.54 & 5.81 & 1.01 & 1.67 & 1.42 \\
\hline OF116374863 & 434 & 7 & 0 & $\begin{array}{l}\text { AID61243.1 lodorant receptor } \\
\text { Calliphora stygia] }\end{array}$ & $\begin{array}{l}7 \mathrm{tm} \_6 \\
\text { superfamily }\end{array}$ & - & 42.02 & 38.13 & 43.94 & 58.6 & 57.21 & 53.83 \\
\hline OF116383925 & 395 & 4 & 0 & $\begin{array}{l}\text { AID61236.1 |odorant receptor, partial } \\
\text { [Calliphora stygia] }\end{array}$ & $\begin{array}{l}7 \mathrm{tm} \_6 \\
\text { superfamily }\end{array}$ & - & 10.74 & 12.37 & 11.41 & 13.63 & 13.22 & 15.09 \\
\hline OF03087 44440 & 215 & 2 & $1.00 \mathrm{E}-90$ & $\begin{array}{l}\text { AID61265.1|gustatory receptor } \\
\text { Calliphora stygia] }\end{array}$ & $\begin{array}{l}7 \mathrm{tm}_{-} 7 \\
\text { superfamily }\end{array}$ & - & 0.02 & 0.02 & 0.04 & 0.02 & 0.02 & 0.02 \\
\hline OF04907 5976 & 382 & 6 & 0 & $\begin{array}{l}\text { AID61224.1 lodorant receptor } \\
\text { [Calliphora stygia] }\end{array}$ & GT1 superfamily & - & 35.9 & 25.1 & 31.57 & 57.74 & 75.76 & 56.73 \\
\hline OF00577 2407 & 461 & 3 & 0 & $\begin{array}{l}\text { XP_023290912.1|putative odorant } \\
\text { receptor 85e [Lucilia cuprina] }\end{array}$ & $\begin{array}{l}7 \mathrm{tm} \_6 \\
\text { superfamily }\end{array}$ & - & 0 & 0 & 0 & 0 & 0.04 & 0 \\
\hline OF09932 5332 & 389 & 6 & 0 & $\begin{array}{l}\text { AID61217.1 |odorant receptor } \\
\text { Calliphora stygia] }\end{array}$ & $7 \mathrm{tm} \_6$ & cl20237 & 5.09 & 4.15 & 4.68 & 5.89 & 8.35 & 5.73 \\
\hline OF09933 7816 & 393 & 6 & 0 & $\begin{array}{l}\text { AID61218.1 lodorant receptor } \\
\text { Calliphora stygia] }\end{array}$ & $7 \mathrm{tm} \_6$ & cl20237 & 9.4 & 7.99 & 10.61 & 6.87 & 7.24 & 6.25 \\
\hline
\end{tabular}




\begin{tabular}{|c|c|c|c|c|c|c|c|c|c|c|c|c|}
\hline OF11666 1703 & 392 & 6 & 0 & $\begin{array}{l}\text { AID61212.1|odorant receptor, partial } \\
\text { [Calliphora stygia] }\end{array}$ & $\begin{array}{l}7 \mathrm{tm} \_6 \\
\text { superfamily }\end{array}$ & - & 6.13 & 8.42 & 7.7 & 11.59 & 8.84 & 6.57 \\
\hline OF11667 745 & 245 & 3 & $\begin{array}{l}1.00 \mathrm{E}- \\
103\end{array}$ & $\begin{array}{l}\text { XP_023296402.1 lodorant receptor 46a- } \\
\underline{\text { like [Lucilia cuprina] }}\end{array}$ & $\begin{array}{l}7 \mathrm{tm} \_6 \\
\text { superfamily }\end{array}$ & - & 0 & 0.14 & 0.14 & 0 & 0.14 & 0 \\
\hline OF008964041 & 347 & 6 & 0 & $\begin{array}{l}\text { AID61211.1 odorant receptor } \\
\text { [Calliphora stygia] }\end{array}$ & $\begin{array}{l}7 \mathrm{tm} \_6 \\
\text { superfamily }\end{array}$ & - & 108.76 & 103.46 & 114.6 & 57.1 & 75.02 & 68.08 \\
\hline OF00900 7334 & 375 & 7 & 0 & $\begin{array}{l}\text { AID61210.1 |odorant receptor } \\
\text { [Calliphora stygia] }\end{array}$ & $7 \mathrm{tm} \_6$ & cl20237 & 37.52 & 22.67 & 30.74 & 51.14 & 54.37 & 41.49 \\
\hline OF00084 & 1206 & 1 & 0 & $\begin{array}{l}\text { XP_023300977.1|uncharacterized } \\
\text { protein LOC111683162 [Lucilia } \\
\text { cuprina] }\end{array}$ & Ig superfamily & - & 0.01 & 0.02 & 0.02 & 0.01 & 0.02 & 0.01 \\
\hline OF0073135001 & 311 & 4 & 0 & $\begin{array}{l}\text { XP } 023301990.1 \mid \text { transmembrane } \\
\text { protein } 47 \text { isoform X1 [Lucilia cuprina }\end{array}$ & - & - & 0.04 & 0.02 & 0.01 & 0.01 & 0.02 & 0.02 \\
\hline OF00834 2837 & 705 & 0 & 0 & $\begin{array}{l}\underline{\text { XP 023301258.1|putative }} \\
\underline{\text { uncharacterized protein }} \\
\underline{\text { DDB_G0292292 [Lucilia cuprina] }}\end{array}$ & $\begin{array}{l}\text { alpha-crystallin- } \\
\text { Hsps_p23-like } \\
\text { superfamily }\end{array}$ & - & 4.6 & 5.12 & 3.6 & 2.59 & 3.94 & 4.57 \\
\hline OF02467 73065 & 564 & 0 & 0 & $\begin{array}{l}\text { KNC22574.1 hypothetical protein } \\
\text { FF38_00190, partial [Lucilia cuprina] }\end{array}$ & Ig_3 & cl11960 & 0.01 & 0.02 & 0.02 & 0.01 & 0.01 & 0.01 \\
\hline
\end{tabular}




\begin{tabular}{|c|c|c|c|c|c|c|c|c|c|c|c|c|}
\hline OF02968 12261 & 223 & 1 & $\begin{array}{l}1.00 \mathrm{E}- \\
146\end{array}$ & $\begin{array}{l}\text { XP_023309200.1|uncharacterized } \\
\text { protein LOC111690855 [Lucilia } \\
\text { cuprina] }\end{array}$ & - & - & 277.64 & 277.72 & 344.84 & 332.6 & 383.69 & 376.79 \\
\hline OF042749170 & 1302 & 0 & 0 & $\begin{array}{l}\text { XP_023302813.1|uncharacterized } \\
\text { protein LOC111684831 「Lucilia } \\
\text { cuprina }\end{array}$ & $\begin{array}{l}\text { PTZ00280 } \\
\text { superfamily }\end{array}$ & - & 0.06 & 0.05 & 0.03 & 0.02 & 0.01 & 0.07 \\
\hline OF042967115 & 218 & 0 & $\begin{array}{l}7.00 \mathrm{E}- \\
136\end{array}$ & $\begin{array}{l}\text { XP } 023305855.1 \text { uncharacterized } \\
\text { protein LOC111687629 isoform X5 } \\
\text { [Lucilia cuprina] }\end{array}$ & - & - & 0.25 & 0.54 & 0.24 & 0.27 & 0.2 & 0.34 \\
\hline OF05495 0 & 767 & 11 & 0 & $\begin{array}{l}\text { KNC33152.1/hypothetical protein } \\
\text { FF38_03670[Lucilia cuprina] }\end{array}$ & Na_H_Exchanger & c101133 & 0.01 & 0.01 & 0.01 & 0.01 & 0.01 & 0.01 \\
\hline OF06445 2695 & 107 & 0 & $6.00 \mathrm{E}-32$ & $\begin{array}{l}\text { KNC21873.1/hypothetical protein } \\
\text { FF38_00598, partial [Lucilia cuprina] }\end{array}$ & - & - & 1.4 & 2.15 & 1.17 & 0.96 & 1.37 & 1.22 \\
\hline OF0678754253 & 401 & 8 & 0 & $\begin{array}{l}\text { XP_023292082.1 lodorant receptor 22c } \\
\text { [Lucilia cuprina] }\end{array}$ & $\begin{array}{l}7 \mathrm{tm} \_6 \\
\text { superfamily }\end{array}$ & - & 0.01 & 0.02 & 0.01 & 0.01 & 0.01 & 0.01 \\
\hline OF07123 15299 & 421 & 7 & 0 & $\begin{array}{l}\text { AID61247.1|odorant receptor, partial } \\
\text { [Calliphora stygia }\end{array}$ & $\begin{array}{l}7 \mathrm{tm} \_6 \\
\text { superfamily }\end{array}$ & - & 0.97 & 1.24 & 0.89 & 0.94 & 1.23 & 1.66 \\
\hline OF0768666956 & 648 & 0 & 0 & $\begin{array}{l}\text { XP_023309492.1|adenylate kinase } \\
\text { isoenzyme } 5 \text { [Lucilia cuprina] }\end{array}$ & ADK & cl17190 & 0.08 & 0.05 & 0.06 & 0.05 & 0.12 & 0.08 \\
\hline OF10581 46004 & 1540 & 0 & 0 & KNC30311.1/hypothetical protein & Chorein_N & cl14987 & 0.04 & 0.05 & 0.01 & 0.02 & 0.03 & 0.03 \\
\hline
\end{tabular}


FF38_03958 [Lucilia cuprina]

XP 023301321.1|putative

\begin{tabular}{|c|c|c|c|c|c|c|c|c|c|c|c|c|}
\hline OF11048 5109 & 147 & 0 & $4.00 \mathrm{E}-43$ & $\begin{array}{l}\text { uncharacterized protein } \\
\text { DDB_G0271606, partial [Lucilia } \\
\text { cuprina] }\end{array}$ & - & - & 0 & 0 & 0 & 0 & 0 & 0.02 \\
\hline OF1105521378 & 246 & 0 & $\begin{array}{l}3.00 \mathrm{E}- \\
147\end{array}$ & $\begin{array}{l}\text { XP } 023298603.1 \text { lleucine-rich repeat- } \\
\text { containing protein } 20 \text { isoform X1 } \\
\text { [Lucilia cuprina }]\end{array}$ & $\begin{array}{l}\text { PLN00113 } \\
\text { superfamily }\end{array}$ & & 6.67 & 9.26 & 7.86 & 23.57 & 11.89 & 8.27 \\
\hline OF11179 13667 & 314 & 0 & $\begin{array}{l}7.00 \mathrm{E}- \\
164\end{array}$ & $\begin{array}{l}\text { XP 023301587.1|ADP-ribosylation } \\
\text { factor } 1 \text { [Lucilia cuprina] }\end{array}$ & $\begin{array}{l}\text { P-loop_NTPase } \\
\text { superfamily }\end{array}$ & c102475 & 0.87 & 0.78 & 0.8 & 0.97 & 0.74 & 0.82 \\
\hline OF11420 ${ }_{8}^{14760}$ & 741 & 0 & 0 & $\begin{array}{l}\text { KNC24737.1|LIM and SH3 domain } \\
\text { protein Lasp [Lucilia cuprina] }\end{array}$ & LIM_LASP & - & 2.3 & 1.99 & 2.16 & 2.15 & 2.62 & 2.37 \\
\hline OF11531 11052 & 180 & 2 & $\begin{array}{l}2.00 \mathrm{E}- \\
112\end{array}$ & $\begin{array}{l}\text { XP 023300793.1|uncharacterized } \\
\text { protein LOC111683003 [Lucilia } \\
\text { cuprina] }\end{array}$ & - & - & 2.12 & 2.25 & 2.34 & 2.4 & 2.63 & 2.33 \\
\hline
\end{tabular}

TMDs: Transmembrane

domains

1 FPKM: Fragments per kilobase of transcript per million mapped reads 